FELIPE TOMACHEVSKI SIQUEIRA

CARACTERIZAÇÃO DAS PROPRIEDADES FÍSICAS E TERMOELÉTRICAS DE FILMES Cu-Ni-P OBTIDOS POR DEPOSIÇÃO QUÍMICA SOBRE SILÍCIO

São Paulo 
FELIPE TOMACHEVSKI SIQUEIRA

\section{CARACTERIZAÇÃO DAS PROPRIEDADES FÍSICAS E TERMOELÉTRICAS DE FILMES Cu-Ni-P OBTIDOS POR DEPOSIÇÃO QUÍMICA SOBRE SILÍCIO}

Dissertação apresentado à

Escola Politécnica da Universidade de São

Paulo para obtenção do título de Mestre em Ciências.

São Paulo

2017 


\section{CARACTERIZAÇÃO DAS PROPRIEDADES FÍSICAS E TERMOELÉTRICAS DE FILMES Cu-Ni-P OBTIDOS POR DEPOSIÇÃO QUÍMICA SOBRE SILÍCIO}

Dissertação apresentado à

Escola Politécnica da Universidade de São

Paulo para obtenção do título de Mestre em Ciências.

Área de Concentração:

Microeletrônica

Orientador: Prof. Dr.

Sebastião Gomes dos Santos Filho

São Paulo 
Este exemplar foi revisado e corrigido em relação à versão original, sob responsabilidade única do autor e com a anuência de seu orientador.

São Paulo, de de

Assinatura do autor:

Assinatura do orientador:

Siqueira, Felipe T.

CARACTERIZAČ̃̃ DAS PROPRIEDADES FÍSICAS E TERMOELÉTRICAS DE FILMES CU-Ni-P OBTIDOS POR DEPOSIÇÃO

QUÍMICA SOBRE SILÍCIO / F. T. Siqueira, S. G. Santos Filho -- versão corr. São Paulo, 2017.

$60 \mathrm{p}$.

Dissertação (Mestrado) - Escola Politécnica da Universidade de São Paulo. Departamento de Engenharia de Sistemas Eletrônicos.

1.filmes Cu-Ni-P 2.P2O5 3.poder termoelétrico 4.deposição eletroquímica I.Universidade de São Paulo. Escola Politécnica. Departamento de Engenharia de Sistemas Eletrônicos II.t. III.Santos Filho, Sebastião G. dos 


\section{DEDICATÓRIA}

Dedico este trabalho aos meus pais, que durante toda a minha vida, por maiores que fossem as dificuldades, nunca me fizeram desacreditar, e sempre se esforçaram para que eu continuasse meus estudos e que pudesse chegar o mais longe possível. À minha avó Maria Ignês Tomazi Tomachevski, responsável pela criação e por vários ensinamentos, por me acolher e cuidar nos momentos mais difíceis dessa minha caminhada.

E ao meu avô, Vlademir Tomachevski (in memorian) que está em algum lugar olhando e torcendo por mim, acreditando sempre que um dia eu serei quem ele sempre sonhou. Obrigado meu grande amigo. 


\section{AGRADECIMENTOS}

Agradeço primeiramente à minha noiva, Karen Karoline Sobrinho, que me apoiou e não me deixou desistir, mesmo nos momentos mais difíceis, quando a distância e o tempo iam contra todos os meus objetivos.

Agradeço aos grandes mestres e professores que tive nessa caminhada, desde o ensino fundamental até a minha graduação, que sempre me mostraram que o caminho para o sucesso sempre começa dentro da sala de aula, e que o respeito e a consideração para com aqueles que passam o conhecimento a frente, deveriam ser primordiais para a vida de qualquer pessoa.

Agradeço ao professor Dr. Sebastião Gomes dos Santos Filho, meu orientador neste trabalho, o qual acreditou em mim, no meu potencial, e me ajudou mais do que qualquer outra pessoa nesta caminhada.

Agradeço também a professora Dra. Marina Sparvoli, que me apresentou o mundo acadêmico de uma outra perspectiva, me ajudou e me incentivou durante todo o período deste trabalho, sendo uma das grandes responsáveis por tudo isso acontecer. 


\section{RESUMO}

Superfícies de silício (100) foram inicialmente pré-ativadas em uma solução diluída de ácido fluorídrico contendo $\mathrm{PdCl}_{2}$. Após essa etapa, filmes finos de $\mathrm{Cu}-\mathrm{Ni}-\mathrm{P}$ foram quimicamente depositados utilizando-se um banho químico contendo $15 \mathrm{~g} / \mathrm{l}$ $\mathrm{NiSO}_{4} .6 \mathrm{H}_{2} \mathrm{O} ; 0.2 \mathrm{~g} / \mathrm{l} \mathrm{CuSO}{ }_{4} .5 \mathrm{H}_{2} \mathrm{O} ; 15 \mathrm{~g} / \mathrm{l} \mathrm{Na} 2 \mathrm{HPO}_{2} . \mathrm{H}_{2} \mathrm{O}$ e $60 \mathrm{~g} / / \mathrm{Na}_{3} \mathrm{C}_{6} \mathrm{H}_{50} \mathrm{O}_{7} .2 \mathrm{H}_{2} \mathrm{O}$ na temperatura de $80^{\circ} \mathrm{C}$ onde foi adicionado $\mathrm{NH}_{4} \mathrm{OH}$ até que o $\mathrm{pH}$ da solução atingisse 8,0. Foi observado que as porcentagens estequiométricas de $\mathrm{Ni}$ e $\mathrm{Cu}$ variaram substancialmente no intervalo de 1 a $3 \mathrm{~min}$, e se tornaram praticamente estáveis em $50 \%$ e $35 \%$, respectivamente, quando o tempo de deposição foi superior a $3 \mathrm{~min}$. Além disso, a porcentagem de $\mathrm{P}$ permaneceu quase constante em torno de 17-18\% para todos os tempos de deposição. A distribuição de alturas nas imagens FE-SEM resultou bimodal para tempos na faixa de 1 e 3 min onde a predominância do modo de maior altura aumentou substancialmente para o tempo de $3 \mathrm{~min}$. Tal fato serviu para corroborar a evolução da morfologia superficial de grãos menores com diâmetros na faixa de 0,02 a $0,1 \mu \mathrm{m}$, predominantemente compostos de $\mathrm{Ni}$, para grãos maiores, na faixa de 0,1 a $0,3 \mu \mathrm{m}$ e predominantemente compostos de $\mathrm{Cu}$. Após um recozimento a $100^{\circ} \mathrm{C}$ durante $10 \mathrm{~min}$ em ambiente $20 \% \mathrm{O}_{2}+80 \% \mathrm{~N}_{2}$, observou-se uma mudança na morfologia superficial em que os aglomerados de fósforo $\left(\mathrm{P}^{\circ}\right)$ desapareceram enquanto que os grãos que compunham a imagem não mudaram substancialmente de tamanho após o recozimento. Apesar do desaparecimento dos aglomerados, a concentração de fósforo ainda apresentou valor semelhante ao valor de antes do recozimento ( 17-18\%). As análises de difração de raios $\mathrm{X}(\mathrm{XRD})$ indicaram o aparecimento de um pico de difração alargado ao redor de 22,60 característico de óxido de fósforo $\left(\mathrm{P}_{2} \mathrm{O}_{5}\right)$ com estrutura vítrea amorfa significando que o fósforo em estado puro foi transformado na sua forma oxidada. Por outro lado, picos substancialmente menos intensos de $\mathrm{NiO}, \mathrm{Ni}_{3} \mathrm{P}$ e $\mathrm{Si}_{5} \mathrm{P}_{6} \mathrm{O}_{25}$ foram observados. Verificou-se também para os filmes recozidos em $\mathrm{N}_{2}+\mathrm{O}_{2}$ que a resistividade aumentou para todos os tempos de deposição e o poder termoelétrico medido resultou quase independente do tempo de deposição e, portanto, foi quase independente da espessura do filme para as diferentes temperaturas medidas na faixa de 40 a $120^{\circ} \mathrm{C}$.

Palavras-chave: filmes $\mathrm{Cu}-\mathrm{Ni}-\mathrm{P}, \mathrm{P}_{2} \mathrm{O}_{5}$, poder termoelétrico, deposição química. 


\section{ABSTRACT}

Silicon surfaces (100) were initially pre-activated in a diluted hydrofluoric acid solution containing $\mathrm{PdCl}_{2}$. After this step, Cu-Ni-P thin films were chemically deposited using a chemical bath containing $15 \mathrm{~g} / \mathrm{I} \mathrm{NiSO}_{4} \cdot 6 \mathrm{H}_{2} \mathrm{O} ; 0.2 \mathrm{~g} / \mathrm{CuSO}_{4} .5 \mathrm{H}_{2} \mathrm{O}$; $15 \mathrm{~g} / \mathrm{l} \mathrm{Na} 2 \mathrm{HPO}_{2} \cdot \mathrm{H}_{2} \mathrm{O}$ e $60 \mathrm{~g} / \mathrm{l} \mathrm{Na}{ }_{3} \mathrm{C}_{6} \mathrm{H}_{5 \mathrm{O}_{7}} .2 \mathrm{H}_{2} \mathrm{O}$ at the temperature of $80^{\circ} \mathrm{C}$ where $\mathrm{NH}_{4} \mathrm{OH}$ was added until the $\mathrm{pH}$ of the solution reached 8.0. It was observed that the stoichiometric percentages of $\mathrm{Ni}$ and $\mathrm{Cu}$ varied substantially for deposition time in the range of 1 to $3 \mathrm{~min}$, and became practically invariant at $50 \%$ and $35 \%$, respectively, when the deposition time was greater than $3 \mathrm{~min}$. In addition, the percentage of $\mathrm{P}$ remained almost constant at around $17-18 \%$ for all the deposition times. The distribution of heights in the FE-SEM images resulted bimodal for times in the range of 1 and $3 \mathrm{~min}$ where the predominance of the higher average height mode increased substantially for the time of $3 \mathrm{~min}$. This fact allowed one to corroborate the superficial morphology passing from smaller grains with diameters in the range of 0.02 to $0.1 \mu \mathrm{m}$, predominantly composed of $\mathrm{Ni}$ to larger grains in the range of 0.1 to $0.3 \mu \mathrm{m}$ with $\mathrm{Cu}$ predominant composition. After an annealing at $100^{\circ} \mathrm{C}$ for $10 \mathrm{~min}$ in a $20 \% \mathrm{O}_{2}+80 \% \mathrm{~N}_{2}$ environment, the phosphorus $\left(\mathrm{P}^{\circ}\right)$ agglomerates disappeared while the size of the grains did not change substantially after the annealing. Despite the disappearance of the agglomerates, the phosphorus concentration still remained unchanged ( 17-18\%). X-ray diffraction (XRD) analysis showed a broad diffraction peak around 22.6을 which is characteristic of an amorphous vitreous structure $\left(\mathrm{P}_{2} \mathrm{O}_{5}\right)$. In addition, substantially less intense peaks showing small amounts of $\mathrm{NiO}, \mathrm{Ni}_{3} \mathrm{P}$ and $\mathrm{Si}_{5} \mathrm{P}_{6} \mathrm{O}_{25}$ were observed. It was also verified for the $\mathrm{N}_{2}+\mathrm{O}_{2}$ annealed films that the resistivity increased for practically all the deposition times and the measured thermoelectric power was almost independent of the deposition time and, therefore, was also independent of the film thickness for the various temperatures in the range from 40 to $120^{\circ} \mathrm{C}$.

Key-words: Cu-Ni-P films, $\mathrm{P}_{2} \mathrm{O}_{5}$, thermoelectric power, Chemical deposition. 


\section{LISTA DE FIGURAS}

Figura 2.1 - Par termoelétrico formado por uma junção quente e uma junção fria $\mathrm{Cu} / \mathrm{Cu}-\mathrm{Ni}$.

Figura 2.2 - Deposição Eletroquímica espontânea sobre uma superfície condutora não catalítica ativada com paládio.

Figura 3.1 - Montagem experimental para medida do poder termoelétrico.

Figura 4.1 - Espectro de RBS típico e simulação para o tempo de imersão de 1 min.

Figura 4.2 - Espectro de RBS típico e simulação para o tempo de imersão de 4 min.

Figura 4.3 - Porcentagens estequiométricas de Ni, Cu e P como uma função do tempo de deposição.

Figura 4.4 - A resistência de folha e espessura como uma função do tempo de

deposição.

Figura 4.5 - FE-SEM Micrografias dos filmes de Cu-Ni-P para tempos de imersão de: (a) $1 \mathrm{~min}$, (b) $2 \mathrm{~min}$, (c) $4 \mathrm{~min}$, (d) $5 \mathrm{~min}$, (e) $7 \mathrm{~min}$ e (f) $10 \mathrm{~min}$

Figura 4.6 - Distribuição de alturas $\mathrm{h}(\mathrm{nm})$ das imagem FE-SEM apresentadas nas figuras $4.5 \mathrm{a}, 4.5 \mathrm{c}$ e $4.5 \mathrm{e}$ para tempos de deposição de $1 \mathrm{~min}$, $3 \mathrm{~min}$ e $7 \mathrm{~min}$, respectivamente.

Figura 4.7 - Distribuição de áreas de grãos $\left(\mathrm{nm}^{2}\right)$ das imagem FE-SEM

apresentadas nas figuras $4.5 \mathrm{a}, 4.5 \mathrm{c}$ e $4.5 \mathrm{e}$ para tempos de deposição de $1 \mathrm{~min}$, 3min

e $7 \mathrm{~min}$, respectivamente.

Figura 4.8 - Imagens FE-SEM de filmes de Cu-Ni-P para deposição durante 2min:

(a) sem recozimento, (b) após recozimento a $100^{\circ} \mathrm{C}$ por $10 \mathrm{~min}$ em $\mathrm{N}_{2}$ e (c) após recozimento a $100^{\circ} \mathrm{C}$ por $10 \mathrm{~min}$ em $20 \% \mathrm{O}_{2}+80 \% \mathrm{~N}_{2}$.

Figura 4.9 - Detalhe da imagem FE-SEM ampliada das ligas Cu-Ni-P logo que depositadas durante $1 \mathrm{~min}$ e não recozidas.

Figura 4.10 - Imagem FE-SEM das ligas $\mathrm{Cu}-\mathrm{Ni}-\mathrm{P}$ recozidas a $100^{\circ} \mathrm{C} \mathrm{em}$

$20 \% \mathrm{O}_{2}+80 \% \mathrm{~N}_{2}$ durante $10 \mathrm{~min}$ para tempos de deposição de: (a) $1 \mathrm{~min}$, (b) $3 \mathrm{~min}$, (c)

$5 \mathrm{~min}$ and (d) $7 \mathrm{~min}$.

Figura 4.11 - Espectro de RBS típico e simulação para o tempo de imersão de 2 min

e após recozimento a $100^{\circ} \mathrm{C}$ em ambiente $20 \% \mathrm{O}_{2}+80 \% \mathrm{~N}_{2}$.

Figura 4.12 - - Porcentagens estequiométricas de $\mathrm{Ni}$, Cu e P como uma função do tempo de imersão para amostras recozidas a $100^{\circ} \mathrm{C}$ durante $10 \mathrm{~min}$ em ambiente de $20 \% \mathrm{O}_{2}+80 \% \mathrm{~N}_{2}$

Figura 4.13 - Medidas XRD das ligas Cu-Ni-P para os tempos de deposição indicados dentro da figura e recozidos a $100^{\circ} \mathrm{C}$ em $20 \% \mathrm{O}_{2}+80 \% \mathrm{~N}_{2}$.

Figura 4.14 - Resistividade como uma função do tempo de deposição para ligas Cu$\mathrm{Ni}-\mathrm{P}$ não recozidas (logo que depositadas) e recozidas a $100^{\circ} \mathrm{C}$ por $10 \mathrm{~min}$ em ambiente de $20 \% \mathrm{O}_{2}+80 \% \mathrm{~N}_{2}$, respectivamente.

Figura 4.15 - Poder termoelétrico como função da temperatura para ligas $\mathrm{Cu}-\mathrm{Ni}-\mathrm{P}$ depositadas por $3 \mathrm{~min}$ sem recozimento e recozidas a $100^{\circ} \mathrm{C}$ por $10 \mathrm{~min}$ em $20 \% \mathrm{O}_{2}+80 \% \mathrm{~N}_{2}$, respectivamente.

Figura 4.16 - Poder termoelétrico de ligas $\mathrm{Cu}-\mathrm{Ni}$-P recozidas a $100^{\circ} \mathrm{C}$ por $10 \mathrm{~min}$ em ambiente de $20 \% \mathrm{O}_{2}+80 \% \mathrm{~N}_{2}$ como função do tempo de deposição para diversas temperaturas de medida. 


\section{LISTA DE ABREVIATURAS}

RBS Rutherford Backscattering Spectrometry (Espectrometria por Retroespalhamento de Rutherford)

FESEM Microscópio eletrônico de varredura de emissão de campo AFM Atomic Force Microscope (Microscópio de Força Atômica).

RTP Rapid Thermal Processing (Processamento Térmico Rápido). 


\section{LISTA DE SÍMBOLOS}

- $\alpha$ : Coeficiente Térmico de Resistividade

- $\beta$ : Coeficiente de Expansão Linear

- $\Delta V:$ diferença de potencial entre as junções.

- $\Delta V r$ : força eletro-motriz gerada por um termopar.

- $\Delta T$ : diferença de temperatura entre $\mathrm{T}_{\mathrm{A}}$ e $\mathrm{T}_{\mathrm{B}}$.

- F.E.M: força eletromotriz ou tensão elétrica (V).

- $h_{S i}$ espessura do silício.

- $h_{\text {CuNi: }}$ espessura do filme da liga Cu-Ni-P.

- $\rho_{s}$ : resistência de folha de um filme fino ( $\Omega /$ quadrado)

- $S_{e q}$ : potência termoelétrica equivalente do sistema substrato de silício/liga Cu-Ni.

- $S_{S i}$ potência termoelétrica do silício.

- $S_{\text {CuNi: }}$ potência termoelétrica da liga cobre-níquel.

$-S_{A}$ : coeficiente de "Seebeck"

- $S_{B}:$ coeficiente do material $B$.

- S : coeficiente "Seebeck" para dois materiais.

- $\sigma_{\text {si: }}$ condutividade elétrica do silício.

- $\sigma_{\text {CuNi: }}$ condutividade elétrica da liga Cobre - Níquel.

- $\mathrm{T}_{\mathrm{Q}}$ : temperatura na junção de dois materiais $\left({ }^{\circ} \mathrm{C}\right)$.

- $\mathrm{T}_{\mathrm{F}}$ : temperatura de referência $\left({ }^{\circ} \mathrm{C}\right)$.

- $\omega_{0:}$ freqüência de ressonância do sistema da mola. 


\section{SUMÁRIO}

1. Introdução, Justivicativas, Objetivos e Organização do Trabalho ................ 12

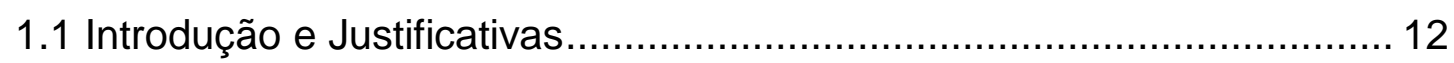

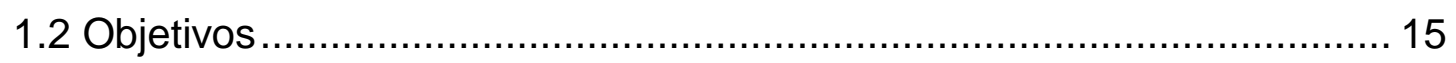

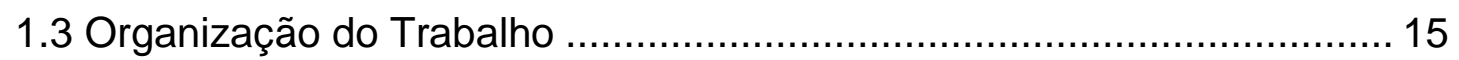

2. Revisão Bibliográfica ............................................................................. 17

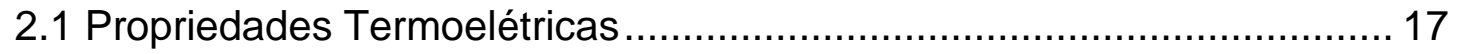

2.2 Deposição de Paládio para Ativação de Superfícies ............................. 19

2.3 Deposição Química..................................................................... 19

2.4 Deposição Química de Ligas Cu-Ni-P ............................................. 23

2.5 Deposição Química sobre Superfícies de Silício ................................ 24

2.6 O Papel dos Aditivos.................................................................. 26

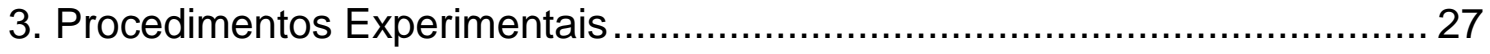

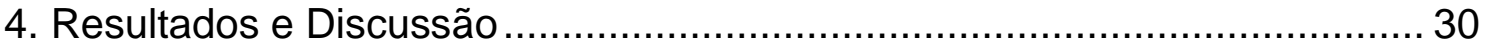

4.1 Obtenção de Filmes de Cu-Ni-P ................................................... 30

4.2 Recozimento de filmes de Cu-Ni-P em ambientes de $\mathrm{N}_{2}$ e $\mathrm{N}_{2}+\mathrm{O}_{2} \ldots \ldots \ldots . . .37$

4.3 Caracterização da poder termoelétrico de filmes de Cu-Ni-P ................ 48

5. Conclusões e Perspectivas Futuras ...................................................... 51

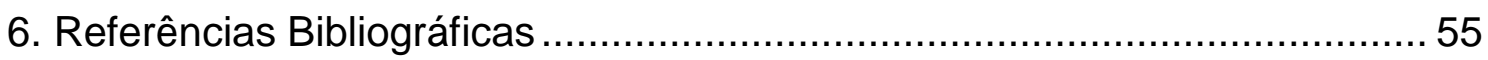




\section{Introdução, Justificativas, Objetivos e Organização do Trabalho}

\subsection{Introdução e Justificativas}

A construção de sensores termoelétricos utilizando filmes finos de cobre e constantan $(50 \% \mathrm{Cu}+50 \% \mathrm{Ni})$ tem sido estudada devido ao alto poder termoelétrico dessa liga (PARK, 2004, DELATORRE, 2003, GLATZ, 2007). As ligas de constantan (CuNi) apresentam resistividade elétrica com coeficiente térmico muito baixo $\left(\alpha=1 \times 10^{75} \mathrm{~K}^{-1}\right.$ ) na faixa de 20 a $600^{\circ} \mathrm{C}$ e coeficiente de expansão linear também muito baixo $\left(\beta=13.5 \times 10^{-6}-16 \times 10^{-6} \mathrm{~K}^{-1}\right)$ para temperaturas na faixa de $100 \mathrm{a}$ $600^{\circ} \mathrm{C}$. Graças à quase invariância dos coeficientes de resistividade e de expansão, o constantan tem sido amplamente empregado na fabricação de resistores de precisão, dispositivos de aquecimento e termopares (GLATZ, 2007; DELATORRE, 2003).

A utilização de lâminas de silício como substrato para a deposição de filmes finos de constantan torna o processo compatível com a tecnologia de microeletrônica, facilitando a sua implementação e permitindo uma produção de baixo custo (TOUIR, 2006). Devido à possibilidade de construção em dimensões reduzidas, é possível construir termopares integrados $\mathrm{Cu} / \mathrm{Cu}-\mathrm{Ni}$ e monitorar as temperaturas diretamente sobre as lâminas de silício durante processos térmicos que exigem alto grau de controle (ROHAN, 2003).

No trabalho de Delatorre (2003) foi apresentado um estudo de deposição da liga Cu-Ni por eletrodeposição com a sua composição variando desde cobre puro até um composto com $25 \%$ em peso de Cu em Ni. Também foram caracterizadas as 
propriedades termoelétricas de camadas depositadas sobre substrato de silício onde constatou-se uma forte influência do substrato.

No trabalho de Parra (2013) foi realizado um estudo inicial da deposição de ligas ternárias Cu-Ni-P por deposição química em substituição ao constantan e foram fabricados termopares $\mathrm{Cu} / \mathrm{Cu}-\mathrm{Ni}-\mathrm{P}$ que apresentaram bons resultados quanto às tensões termoelétricas obtidas que foram semelhantes aos valores medidos em termopares comerciais.

Existem dois tipos de deposição eletroquímica: a deposição química ou auto catalítica (electroless) e a eletrodeposição. Nesta última aplica-se uma diferença de potencial (ou uma corrente) externa entre dois eletrodos de metais diferentes imersos em um eletrólito enquanto que na deposição química (MARQUES, 2003), a reação ocorre sobre um único eletrodo onde uma reação química é catalisada junto à superfície em determinadas condições de $\mathrm{pH}$ e de temperatura da solução sendo que os íons metálicos presentes em solução são reduzidos e depositados (BARKER, 2006; BYEON, 2007). Na eletrodeposição, a corrente convencional que flui entrando no eletrodo é chamada de corrente anódica e a que sai, é chamada corrente catódica. No processo de deposição química ocorrem reações anódica e catódica simultaneamente na superfície de um único eletrodo.

A deposição química (electroless) de ligas do tipo $\mathrm{Ni}-\mathrm{Cu}-\mathrm{P}$ tem sua composição e taxa de deposição controlada pelo pH, temperatura e concentração de íons de $\mathrm{Ni}, \mathrm{Cu}$ e do agente redutor hipofosfito (PARRA, 2013). Esse tipo de filme tem tido aplicação em discos de alumínio para armazenamento de dados em computadores devido às suas propriedades ferromagnéticas (PARRA, 2013; 
GULLA, 1973). Além disso, esse tipo de liga ternária foi empregada na construção de termopares integrados (PARRA, 2013).

Outro tema de estudo muito importante na fabricação de termopares são os óxidos de fósforo vítreos contendo íons de metais de transição que apresentam propriedades semicondutoras e termoelétricas (TAWATI, 2004; MANSINGH, 1978). Tawati (2004) reporta que o óxido de fósforo $\left(\mathrm{P}_{2} \mathrm{O}_{5}\right)$ empregado como matriz passa a ser estável quando na presença de óxidos modificadores, como por exemplo, o NiO. Além desse fato, também é sabido da literatura que o fósforo em estado de oxidação zero $\left(\mathrm{P}^{0}\right)$, presente em ligas $\mathrm{Cu}-\mathrm{Ni}-\mathrm{P}$, pode ser oxidado em baixa temperatura na presença de oxigênio para formar $\mathrm{P}_{2} \mathrm{O}_{5}$ (AVERBUCH-POUCHOUT, 1996).

Por outro lado, o poder termoelétrico de óxidos de fósforo vítreos contendo íons de metais de transição tem sido caracterizados, sendo que em alguns casos tem apresentado características competitivas comparado com as ligas metálicas. Esse é caso das ligas $\mathrm{CoO}-\mathrm{NiO}-\mathrm{P}_{2} \mathrm{O}_{5}, \mathrm{WO}_{3}-\mathrm{P}_{2} \mathrm{O}_{5}, \mathrm{~V}_{2} \mathrm{O}_{5}-\mathrm{P}_{2} \mathrm{O}_{5}, \mathrm{ZnO}-\mathrm{P}_{2} \mathrm{O}_{5}$ onde foi demonstrado que o poder termoelétrico além de assumir valores comparáveis às ligas metálicas, pode apresentar valores relativamente independentes da temperatura (OABI, 2016; TAWATI, 2004; MANSINGH, 1978). No presente trabalho vamos explorar pela primeira vez a presença de $\mathrm{P}_{2} \mathrm{O}_{5}$ nas ligas de $\mathrm{Cu}-\mathrm{Ni}-\mathrm{P}$ depositadas quimicamente após processo de oxidação em baixa temperatura.

Também, no presente trabalho, em continuação aos temas desenvolvidos por Parra (2013), vamos aprofundar o estudo da morfologia das ligas ternárias CuNi-P, vamos estudar a influência do recozimento dos filmes Cu-Ni-P em ambientes contendo oxigênio à baixa temperatura e, finalmente, vamos caracterizar as propriedades termoelétricas dos filmes Cu-Ni-P depositados sobre lâminas de silício. 
Como será mostrado ao longo do presente trabalho, a deposição química tem inúmeras vantagens além de ser um processo de baixo custo (PARRA, 2013; BYEON, 2007).

\subsection{Objetivos}

Os objetivos específicos do presente trabalho foram:

a) caracterização da morfologia de filmes finos Cu-Ni-P obtidos através da deposição química sobre lâminas de silício;

b) caracterização da influência de ambiente oxidante na morfologia e nas propriedades elétricas de filmes finos Cu-Ni-P obtidos através da deposição química sobre lâminas de silício;

c) caracterização das propriedades termoelétricas de filmes finos Cu-Ni-P modificados em ambiente oxidante.

\subsection{Organização do Trabalho}

Nos itens 1.1 e 1.2 anteriores foram apresentados a introdução, as justificativas do trabalho e os objetivos. A seguir, será apresentada a organização dos próximos capítulos 2, 3, 4, 5 e 6 .

No capítulo 2 sobre revisão bibliográfica, são abordadas as definições de algumas propriedades termoelétricas e a forma de medí-las e caracterizá-las. $\mathrm{Na}$ sequência, são apresentados diversos aspectos da deposição química, seus mecanismos e propriedades. 
No capítulo 3 são descritos os procedimentos experimentais empregados na deposição química de metais (electroless) e nas caracterizações físicas, elétricas e termoelétricas dos filmes depositados de Cu-Ni-P.

O Capítulo 4 apresenta os resultados e uma discussão detalhada sobre a deposição química e as caracterizações físicas, elétricas e termoelétricas dos filmes depositados de Cu-Ni-P.

No capítulo 5 são apresentadas as conclusões finais do trabalho assim como desdobramentos e perspectivas a serem desenvolvidas a partir dos resultados obtidos até o momento. 


\section{Revisão Bibliográfica}

Neste capítulo serão abordadas as definições de algumas propriedades termoelétricas e a forma de medí-las e caracterizá-las. Na sequência, serão apresentados diversos aspectos da deposição química, seus mecanismos e propriedades.

\subsection{Propriedades Termoelétricas}

$\mathrm{Na}$ junção de dois metais diferentes, por exemplo, cobre $(\mathrm{Cu})$ e liga constantan (Cu-Ni), é gerada uma força eletro-motriz e seu valor varia com a temperatura da mesma (GARDNER,1994). A figura 2.1 mostra o esquema básico de um par termoelétrico formado por duas junções $\mathrm{Cu} / \mathrm{Cu}-\mathrm{Ni}$ : uma na temperatura $\mathrm{T}_{\mathrm{Q}}$ (junção quente) e a outra na temperatura $T_{F}$ (junção fria).

Figura 2.1 - Par termoelétrico formado por uma junção quente e uma junção fria $\mathrm{Cu} / \mathrm{Cu}-\mathrm{Ni}$.

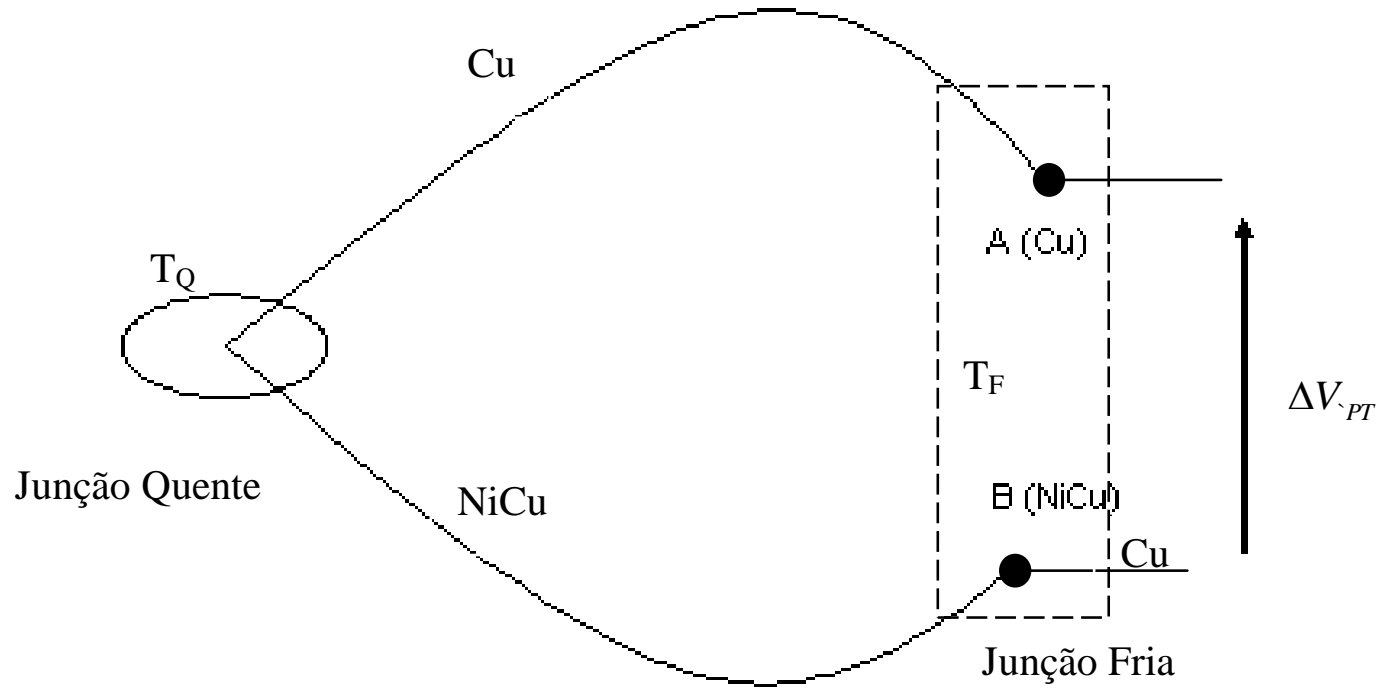

Fonte: Autor

A junção quente $\mathrm{Cu} / \mathrm{Cu}-\mathrm{Ni}$ da figura 2.1 encontra-se na temperatura $T_{Q}$ enquanto que a junção fria $\mathrm{Cu} / \mathrm{Cu}-\mathrm{Ni}$ encontra-se em uma temperatura constante de referência $\mathrm{T}_{\mathrm{F}}$. Uma diferença de potencial termoelétrico $\Delta V_{P T}$ é gerado entre as junções $Q$ e $F$ e depende da diferença de temperatura entre a junção quente $\left(T_{Q}\right)$ e a junção fria $\left(T_{F}\right)(G A R D N E R, 1994)$. 
O coeficiente de "Seebeck" é definido para cada material em relação a platina o qual é dado por:

$$
S_{A}=\frac{\Delta V_{P T}}{\Delta T}
$$

Onde $S_{A}$ é o coeficiente de "Seebeck", $\Delta V_{P T}$ é a diferença de potencial entre as junções quente e fria e $\Delta T$ é diferença de temperatura entre as junções $T_{Q}$ e $T_{F}$.

Um coeficiente "Seebeck" elevado para um dado material indica que o mesmo é mais sensível a mudanças de temperatura. Para um dado par termoelétrico é necessário ao menos dois materiais distintos para gerar uma diferença de potencial $\Delta V_{P T}$. Define-se a Sensibilidade Termoelétrica por (GARDNER,1994):

$$
\mathrm{S}=\mathrm{S}_{\mathrm{B}}-\mathrm{S}_{\mathrm{A}}
$$

onde $S_{B}$ e $S_{A}$ são, respectivamente, os coeficiente de "Seebeck" dos materiais B e A.

A força eletromotriz gerada por um par termoelétrico pode ser obtida através da seguinte relação (GARDNER,1994; BAJZEK,2005):

$$
\Delta V_{P T}=\left(\mathrm{S}_{\mathrm{A}}-\mathrm{S}_{\mathrm{B}}\right) \Delta T
$$

O poder termoelétrico de uma bicamada formada por dois materiais distintos suficientemente espessos é obtido da inclinação da reta do gráfico da Força Eletromotriz $\left(\Delta V_{P T}\right)$ em função da temperatura como segue relação (GARDNER,1994; BAJZEK,2005):

$$
\text { Poder Termoelétrico }=\frac{\Delta V_{P T}}{\Delta T}
$$

O poder termoelétrico de uma bicamada formado por dois materiais suficientemente espessos coincide com a sensibilidade termoelétrica dada pela equação 2.2 (GARDNER,1994). 


\subsection{Deposição de Paládio para Ativação de Superfícies}

A ativação de superfícies de silício por paládio é feita para melhorar a taxa de deposição química em superfícies não catalíticas e o silício é um caso típico. O uso do paládio se deve à sua característica de elemento catalisador para a maioria das reações de deposição química (SKOOG, 1996; WOLFE, 2002; HONG, 2003). Durante sua deposição, o paládio forma sítios que catalisam a deposição química de metal sobre a superfície ativada conforme será visto no ítem 2.3 (MARQUES, 2003).

O processo baseado no mecanismo de deslocamento indireto (MARQUES, 2003) pode ser empregado para depositar sítios superficiais de Pd. A deposição ocorre pela remoção de átomos da superfície do silício através da reação de espécies $\mathrm{F}^{-}$resultantes da dissociação de ácido fluorídrico $(\mathrm{HF})$, descritas pelas reações:

$$
\begin{aligned}
& \mathrm{Si}^{0}+6 \mathrm{~F}^{-} \rightarrow \mathrm{SiF}_{6}^{2-}+4 \mathrm{e}^{-} \text {(oxidação) } \\
& 2 \mathrm{Pd}^{2-}+4 \mathrm{e}^{-} \rightarrow 2 \mathrm{Pd}^{0} \text { (redução) }
\end{aligned}
$$

Conforme será mostrado a seguir, tanto a ativação de superfícies por paládio como a deposição química de metal são processos de oxirredução ou processos eletroquímicos.

\subsection{Deposição Química}

De forma geral, a deposição química ocorre em superfícies catalíticas, ativadas por exemplo com sítios ativos de paládio, em determinadas condições de pH e de temperatura (MALLORY, 1990). Em uma solução de deposição química, os íons metálicos presentes na solução são reduzidos e depositados. A reação eletroquímica que descreve genericamente o processo de deposição química parte da redução de um íon metálico como segue: 


$$
\mathrm{M}^{\mathrm{n}+}+\mathrm{n} \cdot \mathrm{e}^{-} \rightarrow \mathrm{M}^{0}
$$

na qual o metal reduzido $\left(\mathrm{M}^{0}\right)$ deposita sobre a superfície.

Nota-se, portanto, que para ocorrer o processo de deposição química é necessário que uma fonte de elétrons esteja presente na solução ou na superfície, o que significa uma reação de oxidação do tipo:

$$
\mathrm{red}^{\mathrm{n}-} \rightarrow \mathrm{ox}+\mathrm{n} \cdot \mathrm{e}^{-}
$$

onde "red" é o agente redutor e "ox" é o produto da sua oxidação (MALLORY, 1990).

Além do sal que fornece os íons metálicos e do agente redutor, toda solução de deposição química possui agentes complexantes com a função de ligantes ("ligands"), responsáveis pela manutenção dos ions metálicos em solução nas paredes da célula de deposição. Também, os ligantes têm a função de facilitar a dissolução de outros componentes como estabilizantes, surfactantes, assim como outros agentes com funções auxiliares no processo químico, para que o filme apresente características específicas, de acordo com a necessidade de cada aplicação particular (MALLORY, 1990).

No caso específico da deposição de cobre, os íons do metal da reação de redução são obtidos pela dissociação de um sal, geralmente sulfato de cobre $\left(\mathrm{CuSO}_{4}\right)$. Um agente redutor muito utilizado é o hipofosfito de sódio $\left(\mathrm{NaH}_{2} \mathrm{PO}_{2}\right)$, resultando no seguinte processo eletroquímico:

$$
\begin{aligned}
& \text { Redução: } \mathrm{Cu}^{2+}+2 \mathrm{e}^{-} \rightarrow \mathrm{Cu}^{0} \\
& + \\
& \text { Oxidação: } \mathrm{H}_{2} \mathrm{PO}_{2}^{-}+\mathrm{H}_{2} \mathrm{O} \rightarrow \mathrm{H}_{2} \mathrm{PO}_{3}^{-}+2 \mathrm{H}^{+}+2 \mathrm{e}^{-} \\
& \text {Reação completa: } \mathrm{Cu}^{2+}+\mathrm{H}_{2} \mathrm{PO}_{2}^{-}+\mathrm{H}_{2} \mathrm{O} \rightarrow \mathrm{H}_{2} \mathrm{PO}_{3}^{-}+2 \mathrm{H}^{+}+\mathrm{Cu}^{0} \\
& \text { O papel do redutor pode também ser exercido por outros agentes redutores } \\
& \text { como o borohidreto de sódio } \left.(\mathrm{NaBH}), \mathrm{DMAB}-\text { dimetilamina borano }\left(\mathrm{CH}_{3}\right)_{2} \mathrm{NHBH}_{3}\right) \text {, } \\
& \text { fomaldeído }\left(\mathrm{CH}_{3} \mathrm{OH}\right) \text { ou hidrazina }\left(\mathrm{N}_{2} \mathrm{H}_{2}: \mathrm{H}_{2} \mathrm{O}\right)(\mathrm{MALLORY}, 1990) \text {. }
\end{aligned}
$$


Assim como no caso da deposição química de cobre, a deposição seletiva de níquel sem consumo de silício também tem sido empregada já há muito tempo sobretudo em aplicações de engenharia metalúrgica. As primeiras aplicações para contatos em junções semicondutoras datam da década de 50 (SULLIVAN, 1957) utilizando receitas de deposição que, por sua vez, já eram há muito conhecidas na época (BRENNER, 1946a, 1946b, 1947).

A deposição eletroquímica de níquel baseia-se nos mesmos princípios já descritos para o cobre, isto é:

1. Dentro da solução de deposição ocorre uma reação de oxidação que libera elétrons;

2. O níquel iônico dentro da solução deve estar complexado com outra ou outras espécies químicas a fim de impedir que o mesmo receba os elétrons e deposite em toda parte;

3. Deve existir uma superfície catalítica capaz de induzir a reação de redução do níquel apenas em regiões específicas sobre uma superfície. Estas regiões, em geral, são superfícies metálicas pré-ativadas.

A reação de oxidação na solução química de deposição ocorre através da adição de hipofosfito de sódio em meio aquoso conforme segue (HWANG, 1995):

$$
\begin{aligned}
& \mathrm{NaH}_{2} \mathrm{PO}_{2} \rightarrow \mathrm{H}_{2} \mathrm{PO}_{2}^{-}+\mathrm{Na}^{+} \\
& \mathrm{H}_{2} \mathrm{PO}_{2}^{-}+\mathrm{H}_{2} \mathrm{O} \rightarrow \mathrm{H}_{2} \mathrm{PO}_{3}^{-}+2 \mathrm{H}^{+}+2 \mathrm{e}^{-}
\end{aligned}
$$

A equação 2.12 representa a dissolução do hipofosfito de sódio em solução e a equação 2.13 corresponde a reação de oxidação propriamente dita onde temos a geração de elétrons. Por outro lado, a reação de complexação do níquel costuma ser feita com a amônia. Para este fim, podemos adicionar hidróxido de amônio que além de promover a complexação do níquel, também permite ajustar o $\mathrm{pH}$ da solução na faixa de 8 a 10 de forma que a reação 2.13 possa ocorrer. Um fato importante a ser destacado refere-se ao processo de redução que ocorre não 
apenas para o níquel, mas também para o fósforo e o hidrogênio de acordo com as seguintes reações:

$$
\begin{aligned}
& \mathrm{Ni}^{2+}+2 \mathrm{e}^{-} \rightarrow \mathrm{Ni}^{0} \\
& 2 \mathrm{H}^{+}+2 \mathrm{e}^{-} \rightarrow \mathrm{H}_{2} \\
& \mathrm{H}_{2} \mathrm{PO}_{2}^{-}+\mathrm{e}^{-} \rightarrow \mathrm{P}^{0}+2 \mathrm{OH}^{-}
\end{aligned}
$$

Note que a reação 2.15 se processa comcomitantemente com a reação 2.14 e provocará a evolução de hidrogênio dentro do filme de níquel resultando num processo de fragilização do mesmo. A reação 2.16, por sua vez, provocará a incorporação de fósforo nos filmes de níquel depositados, resultando numa fase binária $\mathrm{Ni}(\mathrm{P})$ com concentração típica de fósforo na faixa de 5 a 20\% (DUBLIN, 1992; MALLORY, 1990).

Numa dada solução de deposição contendo cloreto de níquel $\left(\mathrm{NiCl}_{2}\right)$, hidróxido de amônio $\left(\mathrm{NH}_{4} \mathrm{OH}\right)$ e hipofosfito de sódio devemos incluir outros aditivos de forma a minimizar a evolução de hidrogênio no filme depositado e ao mesmo tempo promover a estabilização da solução. Nesse sentido, costuma-se adicionar na solução cloreto de amônio $\left(\mathrm{NH}_{4} \mathrm{Cl}\right)$ e citrato de amônio $\left[\left(\mathrm{NH}_{4}\right)_{2} \mathrm{HC}_{6} \mathrm{H}_{5} \mathrm{O}_{7}\right]$, respectivamente (SULLIVAN, 1957).

Assim como no caso do cobre, as superfícies onde se deseja depositar níquel podem necessitar de um processo de ativação prévio através de sítios de paládio. Estes sítios podem ser depositados tanto nas superfícies metálicas como nas de silício com a ajuda de soluções diluídas contendo íons de paládio e ácido fluorídrico (HF) (DUBLIN, 1992). O mecanismo de deposição de paládio é o mesmo já discutido no ítem 2.2. A figura 2.2 ilustra a evolução das reações 2.13, 2.14, 2.15 e 2.16 junto a um sítio de paládio sobre uma superfície condutora. 
Figura 2.2 - Deposição Eletroquímica espontânea sobre uma superfície condutora não catalítica ativada com paládio.

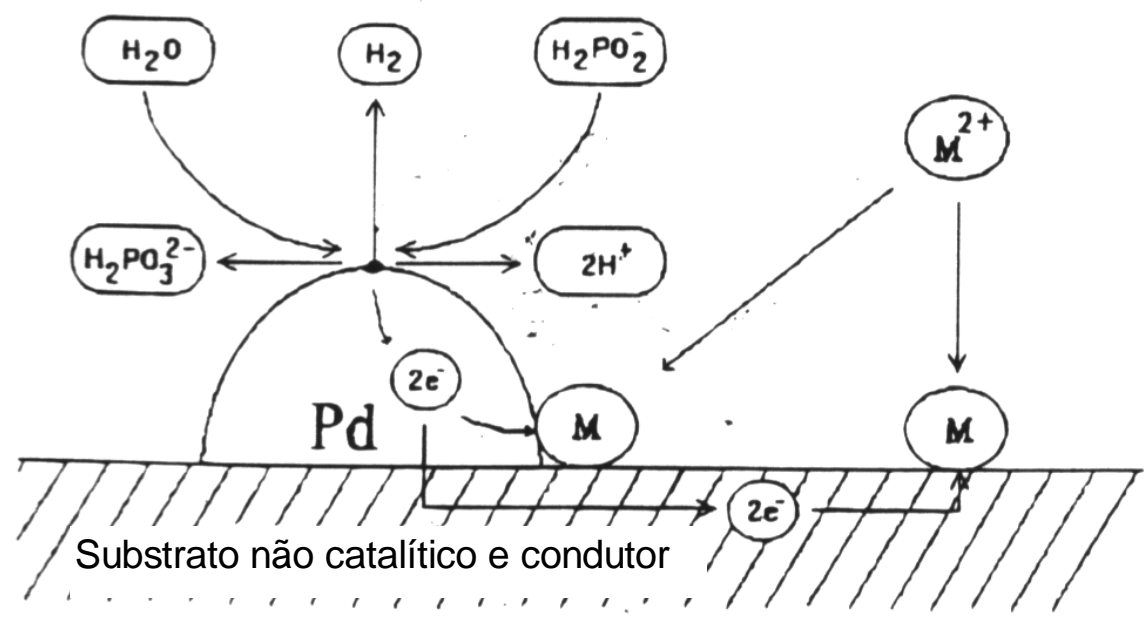

Fonte: Autor

\subsection{Deposição Química de Ligas Cu-Ni-P}

As características da deposição química (electroless) são influenciadas por diversos fatores incluindo a temperatura e $\mathrm{opH}$ da solução de deposição. A quantidade de fósforo dentro da liga Ni-Cu-P determina se a estrutura depositada vai ser amorfa ou cristalina. Estudos anteriores mostraram que a estrutura cristalina $\mathrm{Ni}$ Cu-P se torna amorfa quando a concentração de fósforo é maior que $7 \%$ em peso (CHEN, 1999; MALLORY,1990).

Nas soluções de deposição química, o cobre tem deposição preferencial em virtude do seu alto potencial de redução em relação ao níquel e fósforo (CHEN, 1999). Portanto, a concentração de cobre em solução é um parâmetro de primeira ordem na reação de deposição por causa da grande diferença de potencial de redução (redox) entre $\mathrm{Ni}$ e $\mathrm{Cu}(\approx 1,1 \mathrm{~V})$. A adição de $\mathrm{CuSO}_{4}$ tende a suprimir a incorporação de fósforo o que acaba afetando a estrutura cristalina do filme Ni-Cu-P 
(CHEN, 1999). A literatura sugere que a taxa atômica de Ni/Cu fique entre dois e cinco visando a obtenção de liga compatível com constantan (CHEM, 1999). Isso é obtido usando uma solução (electroless) que tenha taxa atômica Ni/Cu de até 115, um $\mathrm{pH}$ na faixa de 8,5 a 9,0 e temperatura entre de 80 e $95^{\circ} \mathrm{C}$. Como resultado, o filme apresentará estrutura amorfa quando a concentração de $\mathrm{CuSO}_{4}$ estiver na faixa de 0,1 a $0,4 \mathrm{~g} / \mathrm{l}$. Por outro lado, o filme se tornará cristalino para uma concentração de 0,5 g/l de $\mathrm{CuSO}_{4}$ (CHEN, 1999; JONES, 1992).

\subsection{Deposição Química sobre Superfícies de Silício}

A deposição química de metais diretamente sobre o silício é influenciada por fatores cinéticos e termodinâmicos associados à reação de deposição (Marques, 2003).

Existem dois mecanismos que são o resultado do consumo de átomos de silício da superfície para a deposição dos metais. No mecanismo de deslocamento direto, átomos de silício são deslocados da superfície através da reação com $\mathrm{F}^{-}$, gerando os elétrons necessários para promover a deposição de metais. Nesse caso, para cada dois átomos de metal depositados, um átomo de silício é consumido de acordo com as reações de oxidação e redução representadas pelas equações 2.17 e 2.18 (SANTOS,1996), respectivamente.

$$
\begin{aligned}
& \mathrm{Si}^{0}+6 \mathrm{~F}^{-} \rightarrow \mathrm{SiF}_{6}^{2-}+4 \mathrm{e}^{-} \\
& 2 \mathrm{M}^{2+}+4 \mathrm{e}^{-} \rightarrow 2 \mathrm{M}^{0}
\end{aligned}
$$


O segundo mecanismo é chamado de deslocamento indireto no qual o metal, por exemplo, o cobre, pode se depositar sobre o silício consumindo átomos de silício da superfície (SANTOS, 1990). Também é observado que para depositar um átomo de cobre é preciso consumir dois átomos de silício da superfície $\left(\mathrm{Si}^{\mathrm{S}}\right)$, conforme as reações 2.14, 2.15 e 2.16 (SANTOS, 1996):

$$
\begin{aligned}
& 2 \mathrm{Si}=\mathrm{Si}^{\mathrm{S}}\left(\mathrm{O}^{-}\right)_{2}+2 \mathrm{HF} \rightarrow 2 \mathrm{Si}=\mathrm{SiF}_{2}+2 \mathrm{OH}^{-} \\
& 2 \mathrm{Si}=\mathrm{Si}^{\mathrm{S}} \mathrm{F}_{2}+4 \mathrm{~F}^{-}+2 \mathrm{H}^{+} \rightarrow \mathrm{SiF}_{6}^{2-}+2(\mathrm{Si}-\mathrm{H})+2 \mathrm{e}^{-} \\
& \mathrm{M}^{2+}+2 \mathrm{e}^{-} \rightarrow \mathrm{M}^{0}
\end{aligned}
$$

Os dois mecanismos anteriormente mencionado são auto-limitados pela espessura de filme crescido, ou seja, quando toda a superfície estiver recoberta com um filme suficientemente denso, não haverá mais átomos de Si para serem consumidos no sentido de fornecer elétrons para a deposição do metal, assim o filme pára de crescer. O mecanismo sem consumo de Si entra em ação, por exemplo, quando o hipofosfito de sódio é o agente redutor em solução. Nesse caso, o hipofosfito de sódio fornece os elétrons junto à superfície de deposição de forma que os átomos de metal continuam se depositando, propiciando o crescimento do filme. 


\subsection{O Papel dos Aditivos}

Os componentes de uma solução que não são íons metálicos ou agentes redutores são chamados de aditivos. Os aditivos são divididos em dois grupos: os agentes complexantes e os estabilizadores (MALLORY, 1990).

Os agentes complexantes têm a função de prevenir contra a precipitação dos sais metálicos ou do hipofosfito, inibe a dissociação do metal pela redução da concentração de íons livres e protege contra variações bruscas do pH (MALLORY, 1990) .

Os estabilizadores são usados para evitar a decomposição da solução de deposição. Em geral, são utilizados para aumentar a estabilidade temporal das soluções a fim de que possam ser reutilizadas por longos períodos (por exemplo, alguns dias). Os estabilizadores devem possuir uma compatibilidade com os demais componentes da solução para não afetar a reação principal de modo significativo. A concentração do estabilizante é um fator importante que pode inibir a reação por completo e, dependendo do componente utilizado, a sua concentração pode situarse desde a faixa muito residual (0,10 ppm) (MALLORY, 1990). Os estabilizadores podem afetar a taxa de deposição sendo que em geral acabam desacelerando a reação de deposição. 


\section{Procedimentos Experimentais}

Lâminas de silício tipo P com orientação superficial 100, diâmetro de 3

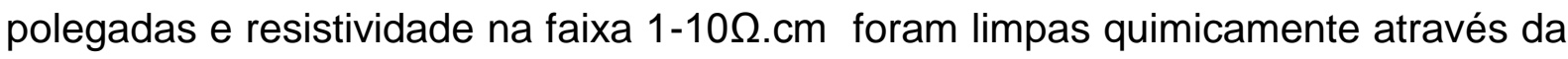
limpeza RCA (KERN, 1970). A receita utilizada para a limpeza RCA consistiu em dois banhos: (a) $400 \mathrm{ml} \mathrm{H}_{2} \mathrm{O}+25 \mathrm{ml} \mathrm{NH}_{4} \mathrm{OH}(38 \%)+175 \mathrm{ml} \mathrm{H}_{2} \mathrm{O}_{2}(37 \%)$ e (b) $400 \mathrm{ml}$ $\mathrm{H}_{2} \mathrm{O}+100 \mathrm{ml} \mathrm{HCl}(38 \%)$, aquecido a $90^{\circ} \mathrm{C}$, por $15 \mathrm{~min}$. Entre cada um dos banhos, as lâminas de silício foram submersas em água deionizada (DI), por 5 min. Em seguida, a pré-ativação de Paládio foi realizada, submergindo amostras em uma solução ácida ( $0.1 \mathrm{~g} / \mathrm{l}$ de $\mathrm{PdCl}_{2}$ e $50 \mathrm{ml} / \mathrm{l}$ de HF) por 60 segundos a fim de obter sítios de Pd na superfície do silício com descrito no ítem 2.2. Finalmente, ligas de CuNi foram quimicamente depositadas nos substratos de $\mathrm{Si}$ utilizando um eletrólito contendo sulfatos de Cu e Ni. A solução utilizada foi de $7.5 \mathrm{~g} / \mathrm{l} \mathrm{NiSO}{ }_{4} .6 \mathrm{H}_{2} \mathrm{O}, 0.2 \mathrm{~g} / \mathrm{I}$ $\mathrm{CuSO}_{4} .5 \mathrm{H}_{2} \mathrm{O}, 7.5 \mathrm{~g} / \mathrm{I} \mathrm{Na} 2 \mathrm{HPO}_{2} \cdot \mathrm{H}_{2} \mathrm{O}, 30 \mathrm{~g} / \mathrm{I} \mathrm{Na} \mathrm{C}_{6} \mathrm{H}_{5} \mathrm{O}_{7} .2 \mathrm{H}_{2} \mathrm{O}, \mathrm{NH}_{4} \mathrm{OH}(\mathrm{pH} \approx 8.0) \mathrm{a}$ $80^{\circ} \mathrm{C}$ e os filmes finos foram depositados por imersão durante o tempo de 1, 2, 3, 4, 5,7 e $10 \mathrm{~min}$.

Após a deposição química das ligas Cu-Ni-P contendo fósforo em estado de oxidação zero $\left(\mathrm{P}^{\circ}\right)$, foi feita a síntese de $\mathrm{P}_{4} \mathrm{O}_{10}$ em ambiente contendo oxigênio $\left(4 \mathrm{P}^{\circ}+5 \mathrm{O}_{2}=\mathrm{P}_{4} \mathrm{O}_{10}\right)($ AVERBUCH-POUCHOUT, 1996) em baixa temperatura o que segundo a literatura é predominante face a formação de óxidos de níquel e cobre e suas ligas (ŽIVKOVIĆ, 1995; RAMANANDAN, 2012). A temperatura foi variada na faixa de 100 a $200^{\circ} \mathrm{C}$ para tempos de processamento variando na faixa de 0 a 30 min. Os fluxos de gases durante os processamentos em baixa temperatura foram de $2 \mathrm{~L} /$ min para $\mathrm{N}_{2}$ ultrapuro ou utilizando uma mistura de $20 \% \mathrm{O}_{2}+80 \% \mathrm{~N}_{2}$. Como apontado na literatura, a síntese de $\mathrm{P}_{4} \mathrm{O}_{10}$ é muito rápida em baixas temperaturas 
em ambientes oxidantes já a partir de $100^{\circ} \mathrm{C}$ em ambiente $20 \% \mathrm{O}_{2}+80 \% \mathrm{~N}_{2}$ situação na qual não ocorre formação apreciável de óxidos de níquel ou cobre e suas ligas (ŽIVKOVIĆ, 1995; RAMANANDAN, 2012).

Espectros RBS foram feitos a 3.0 MeV sob incidência normal de feixe de ${ }^{4} \mathrm{He}^{+}$e com um ângulo de incidência de $170^{\circ}$ usando um acelerador Tanden, modelo 55 DH/NEC. Além disso, o programa SIMNRA (CHU, 1978; MAYER, 1999) foi utilizado para ajustar um espectro simulado ao experimental usando encaixe da composição e concentração da área $\left(\mathrm{N}_{\mathrm{P}}\left(\right.\right.$ átomos $\left.\left./ \mathrm{cm}^{2}\right)\right)$ onde $\mathrm{N}_{\mathrm{P}}$ é proporcional a área de sinal RBS do composto ou elemento formado (CHU, 1978). A porcentagem estequiométrica de $\mathrm{Ni}$, $\mathrm{Cu}$ e $\mathrm{P}$ foram obtidas por meio de valores relativos às áreas de concentração.

A resistência de folha dos filmes foi medida pela sonda de quatro pontas e as características da superfície foram observadas pelo Microscópio eletrônico de varredura de emissão de campo (FESEM).

A figura 3.1 mostra montagem empregada na medida do poder termoelétrico dos filmes Cu-Ni-P (DELATORRE, 2003). Nesta figura observa-se um ponto de referência mantido em uma temperatura baixa de referência $\left(24^{\circ} \mathrm{C}\right)$ utilizando uma placa fria, e outro ponto com uma temperatura controlável na faixa de 50 a $200^{\circ} \mathrm{C}$ com passo de $10^{\circ} \mathrm{C}$, utilizando uma placa quente. 
Figura 3.1 - Montagem experimental para medida do poder termoelétrico.

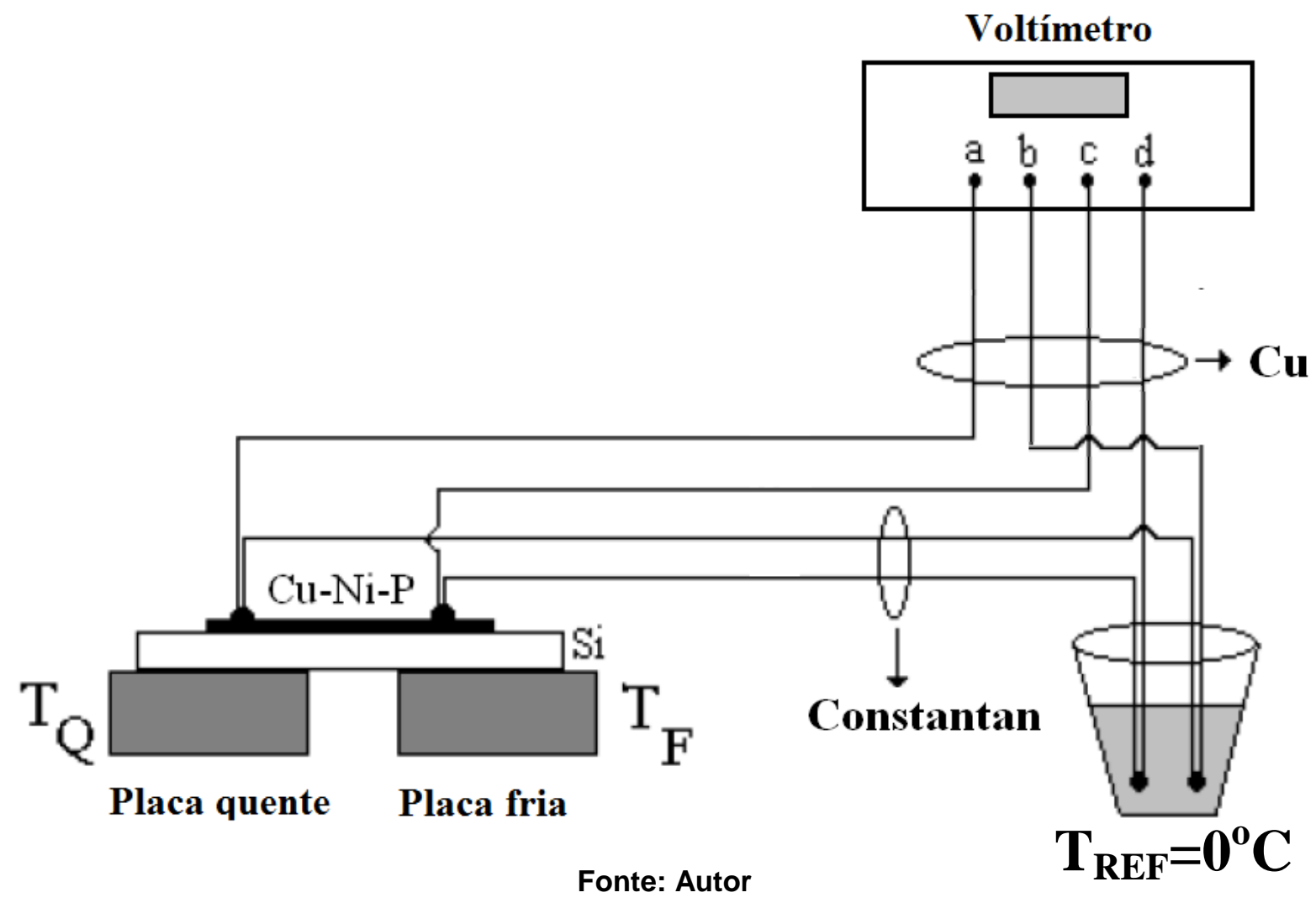

O poder termoelétrico absoluto $S$ dos filmes $\mathrm{Cu}-\mathrm{Ni}-\mathrm{P}$ foi calculado utilizando a equação 3.1 indicada a seguir (DELATORRE, 2003):

$$
S\left(T_{a v}\right)=-\frac{V_{a}-V_{d}}{T_{Q}-T_{F}}+S_{C u N i}\left(T_{a v}\right)=-\frac{\Delta V}{\Delta T}+S_{C u N i}\left(T_{a v}\right)
$$

onde,

$T_{a v}=\frac{T_{Q}+T_{F}}{2}$

e $S_{\text {CuNi }}$ é o poder termoelétrico do Constantan como função da temperatura, conforme reportado na literatura (BLATT, 1976). 


\section{Resultados e Discussão}

Neste capítulo são apresentados os resultados e uma discussão detalhada sobre a deposição química e as caracterizações físicas, elétricas e termoelétricas dos filmes depositados de Cu-Ni-P.

\subsection{Obtenção de Filmes de Cu-Ni-P}

Inicialmente foram realizados vários testes com diferentes concentrações de $\mathrm{NiSO}_{4}, \mathrm{CuSO}_{4}$ e $\mathrm{Na}_{2} \mathrm{HPO}_{2}$ em um pH fixo de 8,0 em uma temperatura também fixa de $80^{\circ} \mathrm{C}$. A adição de cobre influencia a reação de deposição química devido à grande diferença de potencial redox entre Ni e Cu (DELATORRE, 2003).

Figura 4.1 - Espectro de RBS típico e simulação para o tempo de imersão de 1 min.

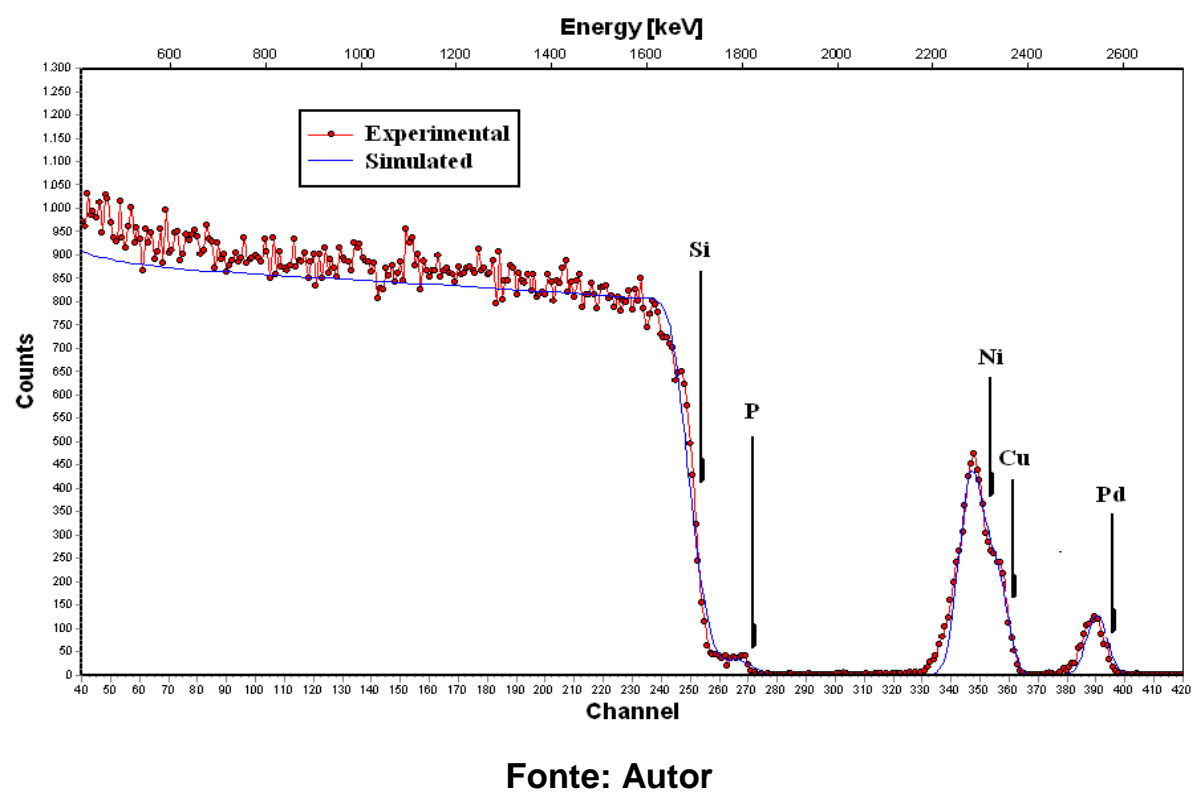

O cobre é preferencialmente depositado devido ao seu elevado potencial de redução em relação ao níquel e o fósforo. Assim, foi estabelecido que uma razão 
atômica de Ni/Cu de pelo menos 70 na solução química para a obtenção da razão de 0,5 de Ni/Cu no depósito. Após o processo de deposição, os filmes depositados com Cu-Ni-P foram analisados através do RBS, o qual foi interpretado pelo programa SIMNRA v.6 (MAYER, 1999). A figura 4.1 mostra o espectro de RBS típico e a curva simulada para um tempo de imersão de 1 min. Neste caso, os sinais de $\mathrm{Cu}$ e Ni são parcialmente sobrepostos, uma vez que as massas atômicas estão muito próximas. Entretanto, o programa SIMNRA permite que se separe ambas as contribuições por ajustamento dos sinais, a fim de obter a composição e concentração da área. As curvas ajustadas são ilustradas sobrepostas, às experimentais e, como resultado, os erros inferiores a $5 \%$ foram obtidos durante a extração das concentrações aéreas relativas de $\mathrm{Ni}$, Cu e P.

Figura 4.2 - Espectro de RBS típico e simulação para o tempo de imersão de 4 min.

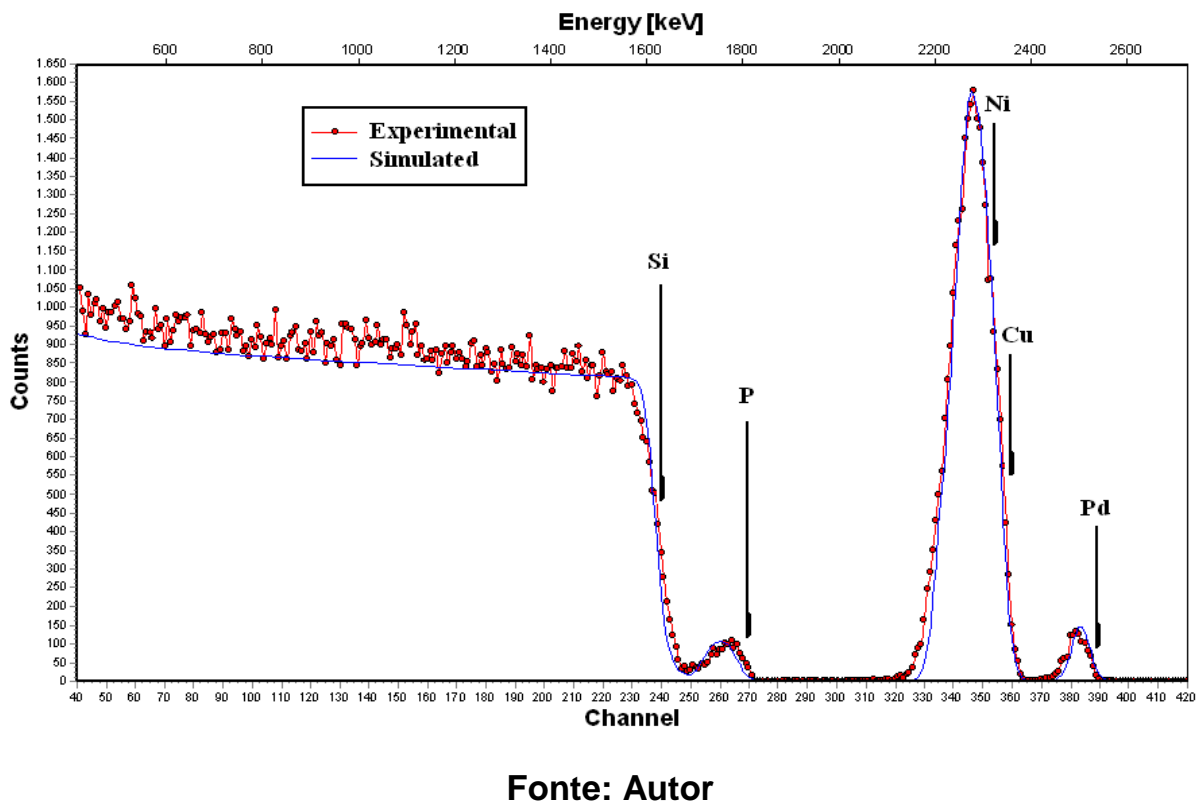

Além disso, a figura 4.2 também mostra o espectro de RBS típico e a curva simulada para o tempo de imersão de 4 min onde os sinais de $\mathrm{Cu}$ e $\mathrm{Ni}$ se 
tornaram quase inteiramente sobrepostos, uma vez que a área sob o sinal de $\mathrm{Cu}-\mathrm{Ni}$ (concentração planar) foi substancialmente aumentada, se comparada com o espectro mostrado na figura 4.1. No entanto, o programa SIMNRA permite separar ambas as contribuições pelo ajuste dos sinais de $\mathrm{Cu}$ e $\mathrm{Ni}$.

Figura 4.3 - Porcentagens estequiométricas de $\mathrm{Ni}$, Cu e P como uma função do tempo de deposição.

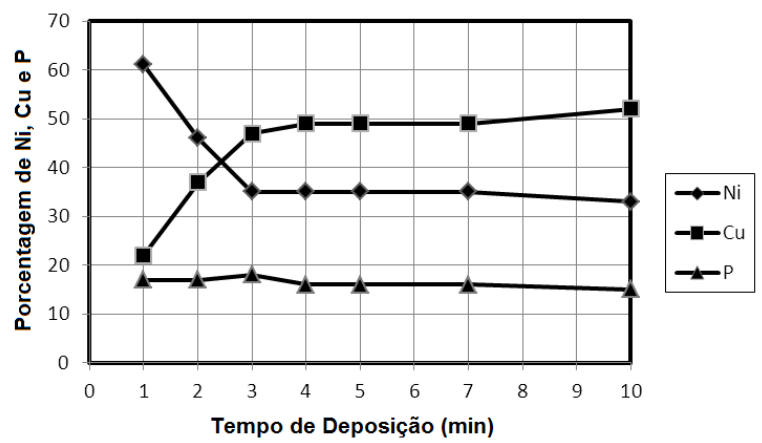

Fonte: Autor
Figura 4.4 - Resistência de folha e espessura como uma função do tempo de deposição.

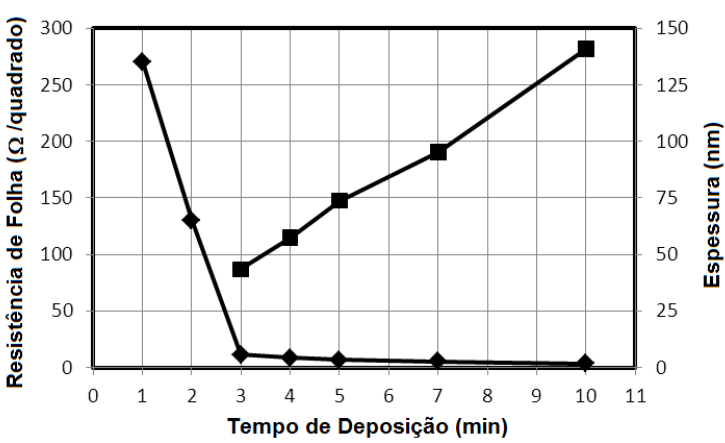

Fonte: Autor

A figura 4.3 ilustra a porcentagem estequiométrica de Ni, Cu e P como uma função do tempo de deposição. É notável que as porcentagens estequiométricas de $\mathrm{Ni}$ e Cu variam substancialmente nos tempos de imersão entre 1 e 3 min e começam a ficar estáveis em $50 \%$ e 35\%, respectivamente, quando o tempo de imersão é maior do que 3min. A porcentagem de $\mathrm{P}$ permanece constante entre $17-18 \%$ durante todo o tempo de deposição estudado e a resistência de folha também varia substancialmente durante a imersão entre 1 e $3 \mathrm{~min}$. A figura 4.4 sugere uma mudança continua na estrutura morfológica para tempos de imersão entre 1 e 3 min o que foi comprovado através das medidas FE-SEM mostradas na figura 4.5. 
Figura 4.5 - Micrografias FE-SEM dos filmes de Cu-Ni-P para tempos de imersão de: (a) $1 \mathrm{~min}$, (b) $2 \mathrm{~min}$, (c) $4 \mathrm{~min}$, (d) $5 \mathrm{~min}$, (e) $7 \mathrm{~min}$ e (f) $10 \mathrm{~min}$ (mesma escala de $1 \mu \mathrm{m}$ indicada no rodapé de cada figura).

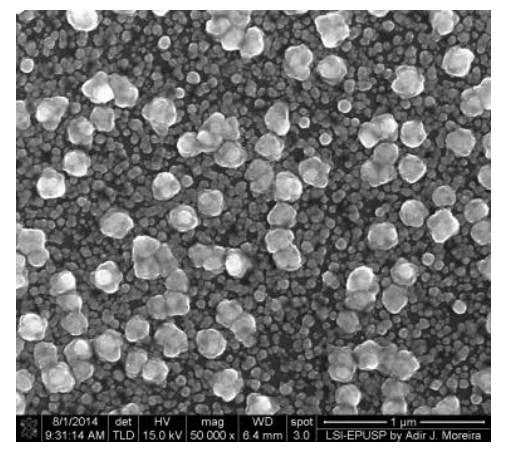

(a) $1 \mathrm{~min}$

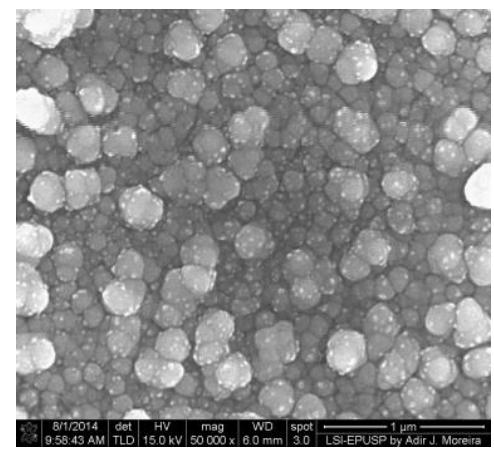

(c) 3 min

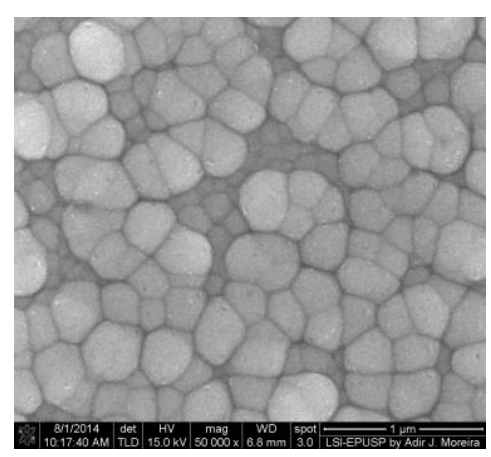

(e) $7 \mathrm{~min}$

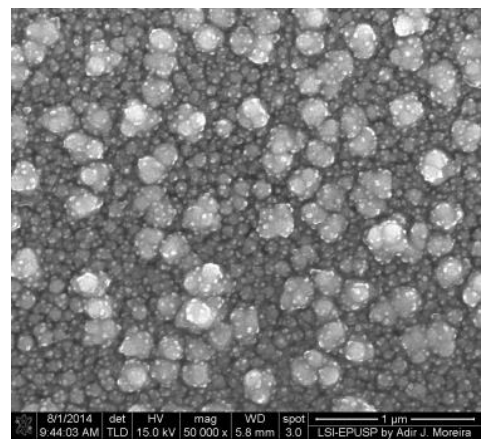

(b) 2 min

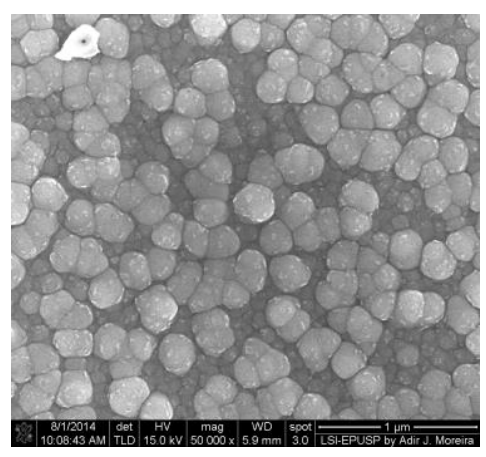

(d) $5 \mathrm{~min}$

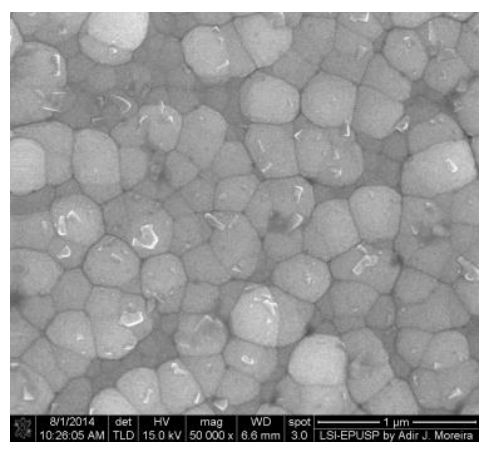

(f) $10 \mathrm{~min}$

Fonte: Autor

A resistência de folha foi medida por meio da técnica de sonda de quatro pontas, e a espessura foi estimada pela relação entre a resistividade de referência do constantan $(49 \mu \Omega . c m)$ (MALLORY, 1990) e a resistência de folha medida. Foi interessante notar que a resistência de folha apresenta uma grande mudança nos tempos de imersão na faixa de 1 a 3min, que está estreitamente correlacionada com a grande mudança de estequiometria observada nos mesmos intervalos de tempo 
de imersão. Por outro lado, como seria de se esperar, a resistência da folha é substancialmente menor para os tempos de imersão superiores a 3 min. Para esclarecer como ocorreu a evolução morfológica, as características da superfície foram observadas por FESEM como mostrado na figura 4.5.

A partir de micrografias por FESEM apresentadas na Figura 4.5, é evidente que os grãos menores com diâmetros na faixa de 0,02 a $0,1 \mu \mathrm{m}$ são inicialmente crescidos na superfície de silício, onde é visível regiões de silício exposta sem depósitos, para tempos de imersão de 1 min e 2 min. A figura $4.5 \mathrm{c}$ já mostra uma superfície sem regiões expostas para o tempo de imersão de 3min (muito semelhante ao obtido para $4 \mathrm{~min}$, não mostrado), o que significa uma grande mudança na morfologia superficial como já foi apontado pelos resultados da estequiometria e a resistência de folha.

Para tempos de deposição na faixa de 1 a $3 \mathrm{~min}$, existe correlação direta entre o tipo de morfologia observada (figura 4.5) e as porcentagens de $\mathrm{Ni}$ e $\mathrm{Cu}$ obtidas (figura 4.3). É importante destacar que o fundo predominante de grãos menores nas figuras $4.5 \mathrm{a}$ e $4.5 \mathrm{~b}$ estão claramente associados a uma maior porcentagem de Ni o que permite inferir que os grãos menores com diâmetros na faixa de 0,02 a $0,1 \mu \mathrm{m}$ são predominantemente compostos de Ni. Por outro lado, a medida que o tempo de deposição cresce, a porcentagem de Ni cai e a porcentagem de Cu sobe o que também permite inferir que os grãos maiores na faixa de 0,1 a $0,3 \mu \mathrm{m}$ são predominantemente compostos de $\mathrm{Cu}$.

A figura 4.6 mostra as distribuições de alturas extraídas das imagens apresentadas nas figuras $4.5 \mathrm{a}, 4.5 \mathrm{c}$ e $4.5 \mathrm{e}$, respectivamente, obtidas com a ajuda do programa IMAGEJ (software open source). É importante destacar que a distribuição de alturas é bimodal para os tempos de 1 e 3 min onde a predominância do modo de 
maior altura aumenta substancialmente para o tempo de $3 \mathrm{~min}$. Tal fato corrobora quantitativamente a mudança da morfologia superficial para tempos na faixa de 1 a 3 min como já descrito anteriormente, isto é, a mudança de grãos pequenos com composição predominante de níquel para grãos maiores com composição predominante de cobre. Por outro lado, a figura 4.6 também mostra para o tempo de 7 min uma distribuição de alturas monomodal o que também é consistente tanto com o fato da superfície estar completamente fechada com os grãos maiores (veja figura 4.5e) assim como também é consistente com o aumento de espessura (valor médio da altura próximo a $70 \mathrm{~nm})$.

Figura 4.6 - Distribuição de alturas $\mathrm{h}(\mathrm{nm})$ das imagem FE-SEM apresentadas nas figuras 4.5a, 4.5c e 4.5e para tempos de deposição de $1 \mathrm{~min}$, $3 \mathrm{~min}$ e $7 \mathrm{~min}$, respectivamente.

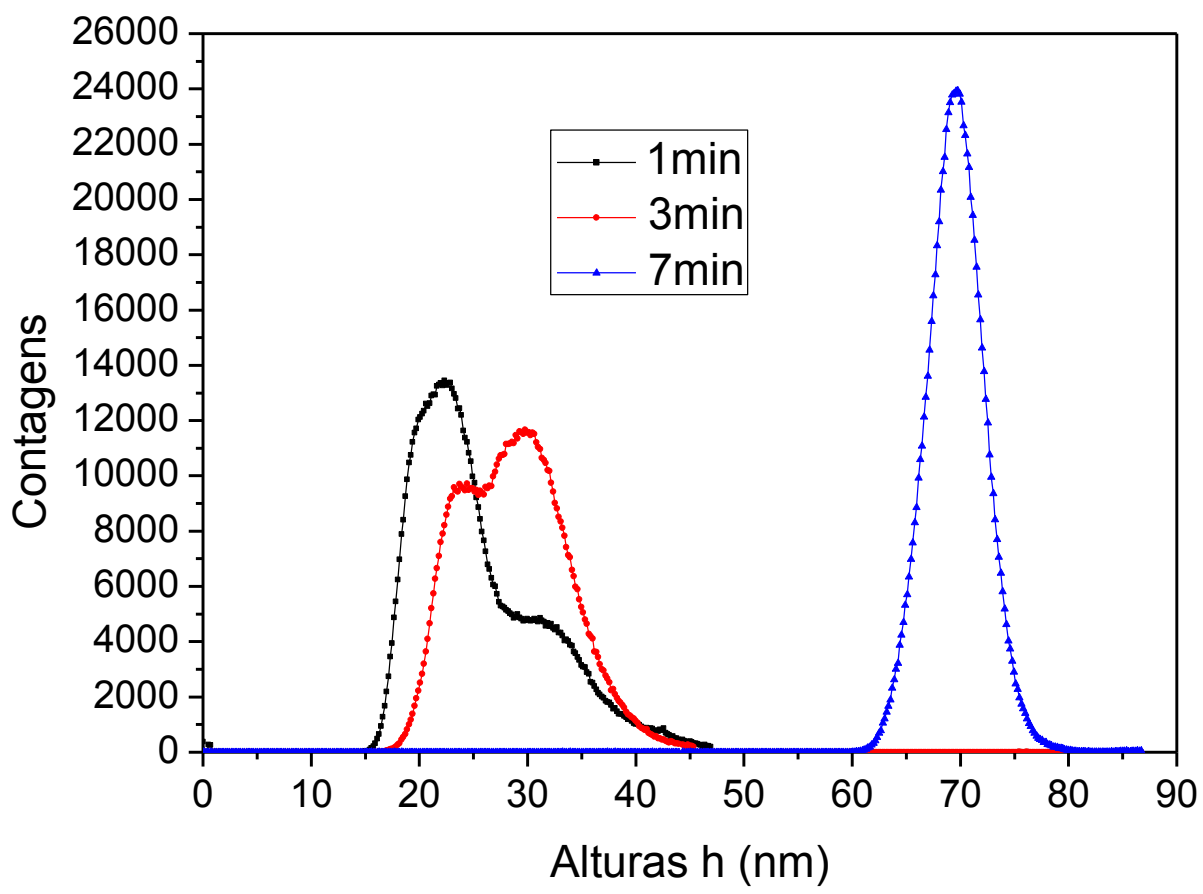

Fonte: Autor 
Figura 4.7 - Distribuição das áreas dos grãos $(\mu \mathrm{m})$ das imagens FE-SEM apresentadas nas figuras $4.5 \mathrm{a}$, $4.5 \mathrm{c}$ e $4.5 \mathrm{e}$ para tempos de deposição de $1 \mathrm{~min}, 3 \mathrm{~min}$ e $7 \mathrm{~min}$, respectivamente.

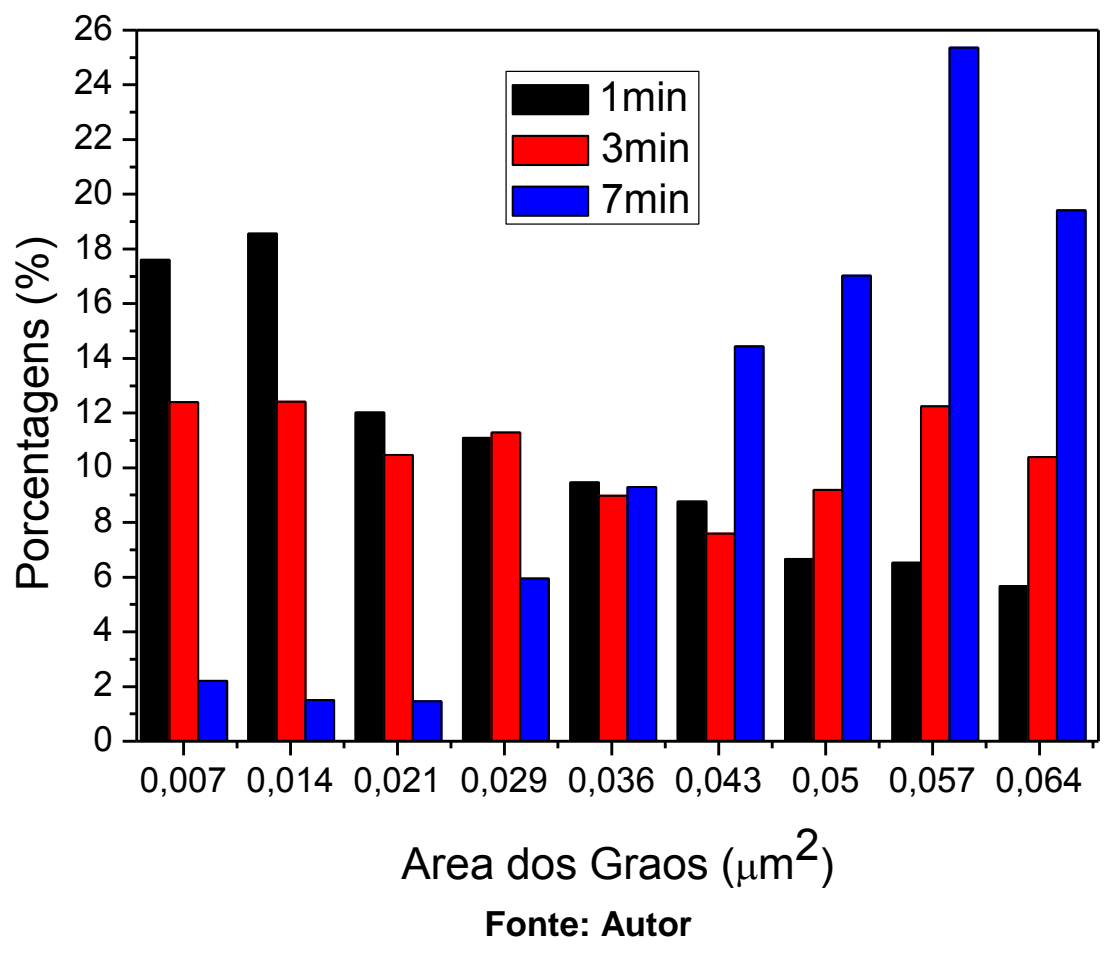

A figura 4.7 mostra as distribuições de áreas de grãos extraídas das imagens apresentadas nas figuras $4.5 \mathrm{a}, 4.5 \mathrm{c}$ e $4.5 \mathrm{e}$, respectivamente, obtidas com a ajuda do programa IMAGEJ (software open source). É importante destacar que a distribuição para o tempo de 1 min mostra que existe maior porcentagem de áreas menores na faixa de 0,007 a $0,021 \mu \mathrm{m}^{2}$. Para o tempo de $3 \mathrm{~min}$, essa maior porcentagem de áreas menores diminui sendo que em 7 min temos predominância de tamanhos de grãos maiores na faixa de 0,036 a $0,064 \mu \mathrm{m}^{2}$. Tal fato corrobora quantitativamente a mudança da morfologia superficial quando o tempo de deposição passa de $1 \mathrm{~min}$ para $7 \mathrm{~min}$ como já descrito anteriormente, isto é, a mudança de grãos pequenos com composição predominante de níquel para grãos maiores com composição predominante de cobre.

Para tempos de deposição maiores que 3min, o diâmetro dos grãos tende a ficar maior sendo que a superfície fica quase que completamente "fechada" para 
tempos de deposição a partir de 7 min. Esta evolução do tamanho do grão pode ser correlacionada com a redução concomitante da resistência de folha de 11,3 para $3,5 \Omega /$ quadrado para tempos de imersão variando na faixa de 3 a $10 \mathrm{~min}$. Portanto, as descontinuidades e não uniformidades dos filmes para tempos na faixa de 1 a $3 \mathrm{~min}$ são os responsáveis pelos maiores valores observados de resistência de folha e maior valor da relação entre as porcentagens de Ni e Cu.

Durante a evolução observada nas porcentagens de Ni e Cu na figura 4.4, a porcentagem de $\mathrm{P}$ permanece quase que inalterada. No próximo ítem 4.2 , será mostrado que a profusão de pontos claros que são observáveis nas figuras $4.5 \mathrm{a}$, 4.5b e 4.5c são na verdade aglomerados de fósforo em estado de oxidação zero $\left(\mathrm{P}^{\circ}\right)$ que mais tarde deixam de ser visíveis nas figuras $4.5 \mathrm{~d}, 4.5 \mathrm{e}$ e $4.5 \mathrm{f}$ após o fechamento total da superfície pelos grãos de maior diâmetro.

\subsection{Recozimento de filmes de $\mathrm{Cu}-\mathrm{Ni}-\mathrm{P}$ em ambientes de $\mathrm{N}_{2}$ e $\mathrm{N}_{2}+\mathrm{O}_{2}$}

A figura 4.8 mostra as imagens FE-SEM dos filmes de Cu-Ni-P obtidos por deposição química durante 2 min de acordo com a receita descrita no capítulo 3 sobre procedimentos experimentais. A figure 4.8a mostra a morfologia superficial do filme após a deposição enquanto que as figuras 4.8b e 4.8c mostram o mesmo filme recozido a $100^{\circ} \mathrm{C}$ por $10 \mathrm{~min}$, respectivamente, em ambientes de $\mathrm{N}_{2}$ (figure $4.8 \mathrm{~b}$ ) e $20 \% \mathrm{O}_{2}+80 \% \mathrm{~N}_{2}$ (figure $4.8 \mathrm{c}$ ). É possível observar na figura $4.8 \mathrm{a}$ (figura $4.6 \mathrm{a}$ ampliada) uma distribuição bimodal de grãos de tamanho menor e grãos de tamanho

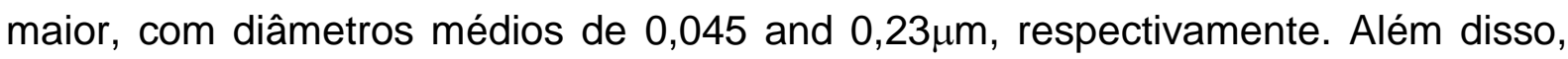
depositados sobre todos os grãos (grandes e pequenos), observam-se grãos claros de tamanho ainda menor (diâmetro médio de $0,028 \mu \mathrm{m}$ ) que foram associados a 
aglomerados de fósforo $\left(\mathrm{P}^{\circ}\right)$ dado que apresentam brilho intenso e alto contraste (GOLDSTEIN, 2003;ECHLIN, 2010; REIMER, 1998).

Figura 4.8 - Imagens FE-SEM de filmes de Cu-Ni-P para deposição durante $2 \mathrm{~min}$ : (a) sem recozimento, (b) após recozimento a $100^{\circ} \mathrm{C}$ por $10 \mathrm{~min}$ em $\mathrm{N}_{2}$ e (c) após recozimento a $100^{\circ} \mathrm{C}$ por 10 min em $20 \% \mathrm{O}_{2}+80 \% \mathrm{~N}_{2}$.

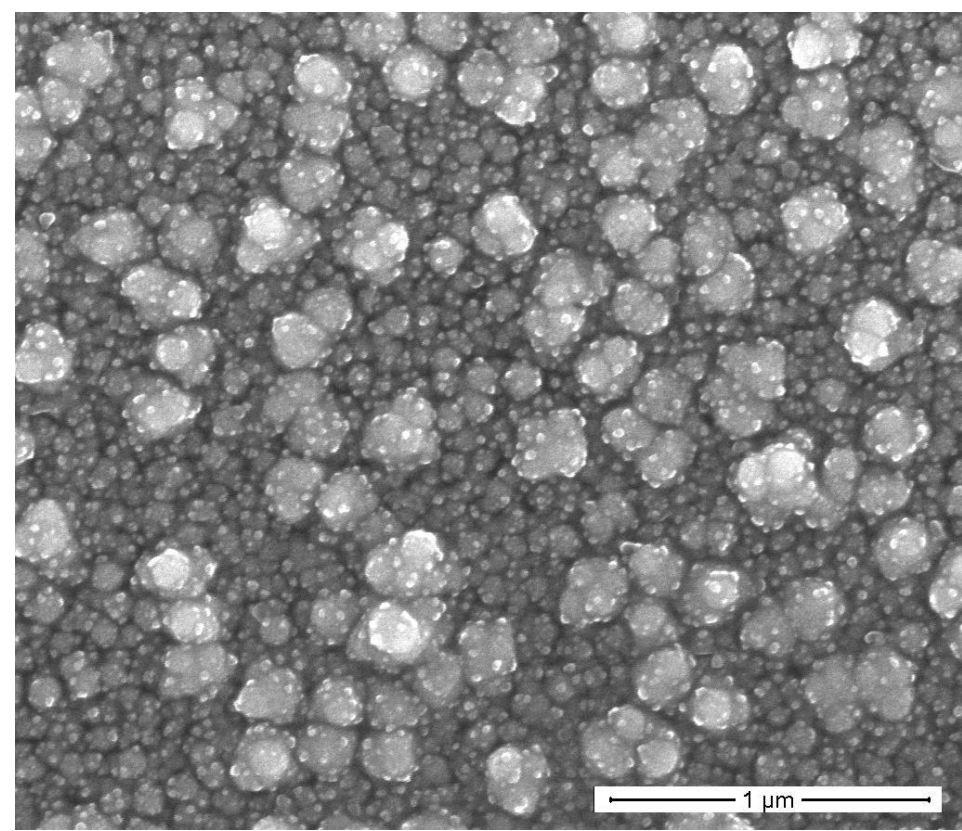

(a)

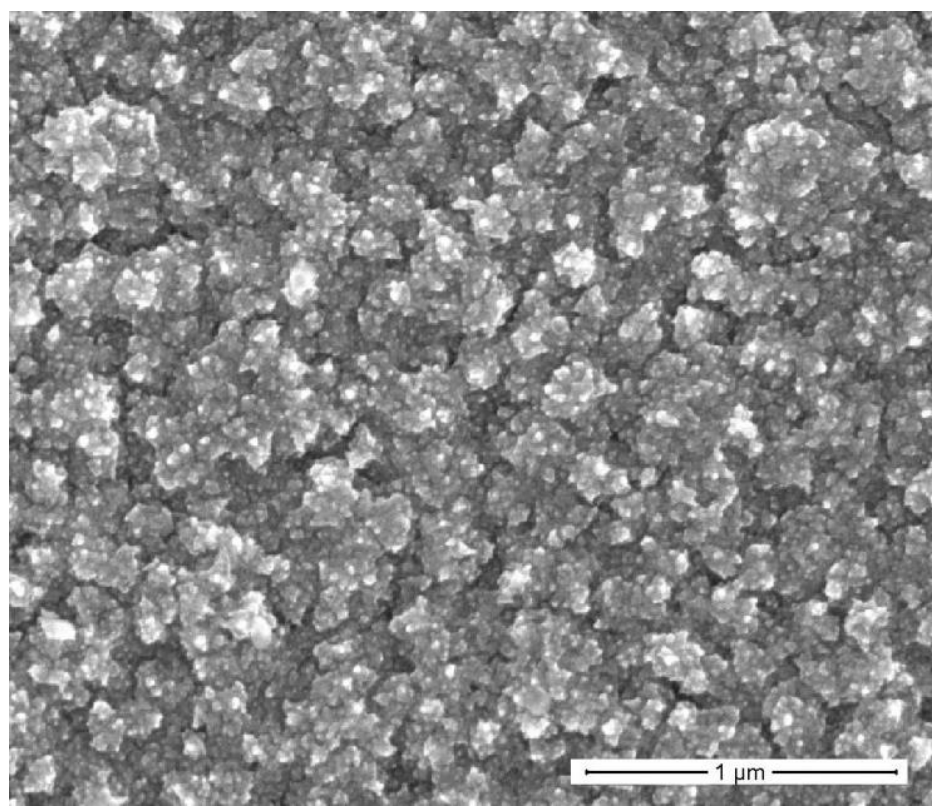

(b)

(continua na próxima página) 


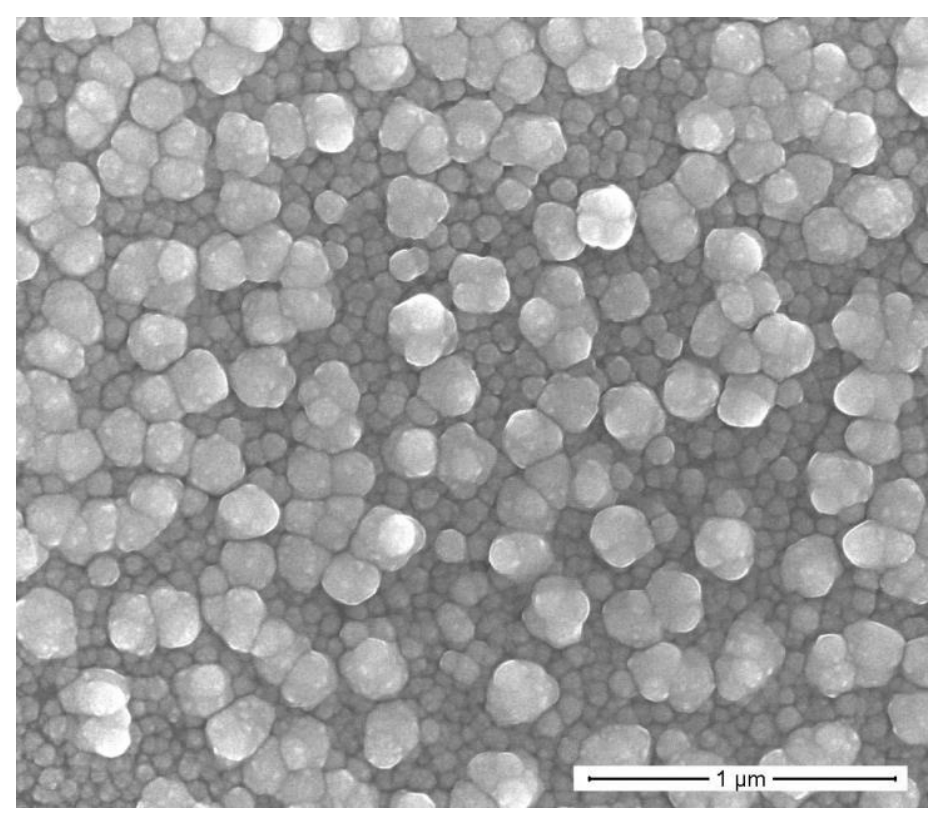

(c)

Fonte: Autor

A imagem FE-SEM na figura 4.9 está em escala ampliada com a imagem da figura 4.8a e apresenta em destaque os grãos com composição associada ao fósforo $\left(\mathrm{P}^{\circ}\right)$ os quais, de acordo com a literatura, é um material cintilante na análise FE-SEM (GOLDSTEIN, 2003;ECHLIN, 2010; REIMER, 1998) que costuma ser empregado como cobertura e, por isso, aparecem na imagem com maior brilho e maior contraste. Esses grãos de menor tamanho (diâmetro médio de 0,028 $\mu \mathrm{m}$ ) aparecem de forma bem delineada sobre toda a superfície do filme sendo que os tratamentos posteriores realizados em ambientes de $\mathrm{N}_{2}$ ultrapuro e de $20 \% \mathrm{O}_{2}+80 \% \mathrm{~N}_{2}$ irão resultar em novas evidências no sentido de corroborar que a composição inicial deles é o fósforo em estado de oxidação zero $\left(\mathrm{P}^{\circ}\right)$. 
Figura 4.9 - Detalhe da imagem FE-SEM ampliada das ligas Cu-Ni-P logo que depositadas durante $1 \mathrm{~min}$ e não recozidas.

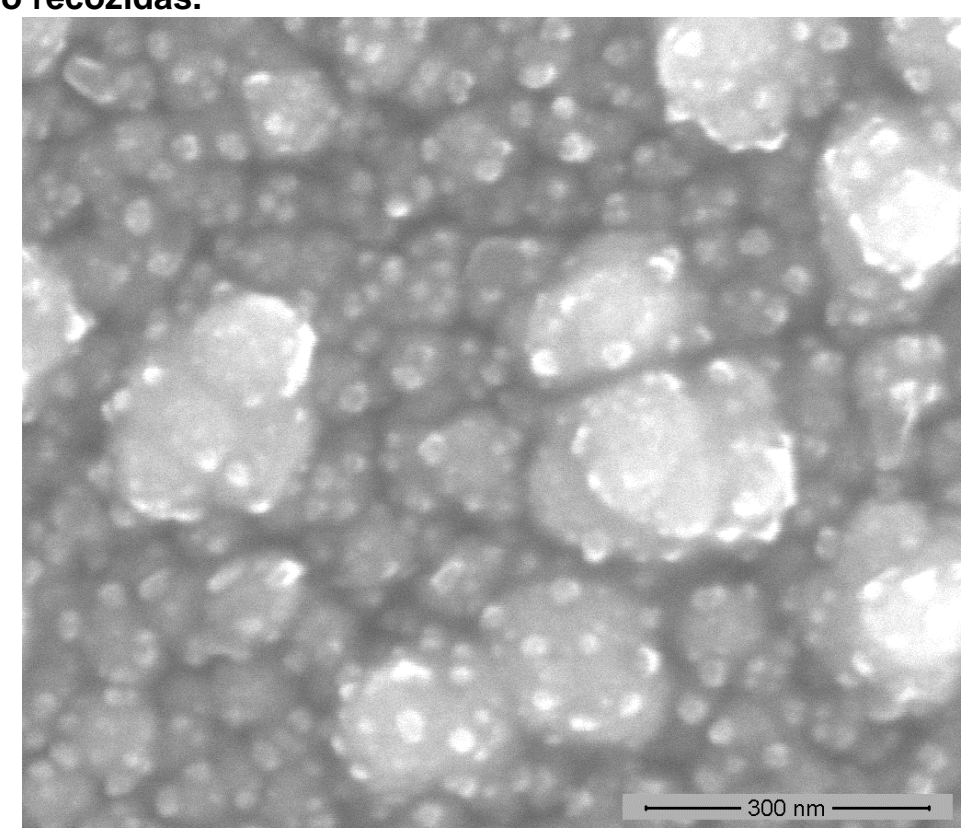

Fonte: Autor

Após o recozimento a $100^{\circ} \mathrm{C}$ durante $10 \mathrm{~min}$ em $\mathrm{N}_{2}$ ultrapuro (figura $4.8 \mathrm{~b}$ ), os grãos mais escuros coalescem em algum grau e começam a aparecer fissuras e rachaduras, possivelmente devido ao efeito de tensionamento mecânico proveniente em parte da tendência de coalescência. Observa-se na superfície "plaquetas" não circulares com grão coalescidos com tamanhos variando na faixa de cerca de de 0,2 e $0,5 \mu \mathrm{m}$ e grãos claros que estão associados a aglomerados de fósforo $\left(\mathrm{P}^{\circ}\right)$, agora com diâmetro médio um pouco maior de $0,032 \mu \mathrm{m}$ comparado ao caso sem recozimento (figura $4.8 \mathrm{a})$.

Após o recozimento a $100^{\circ} \mathrm{C}$ durante 10 min em ambiente $20 \% \mathrm{O}_{2}+80 \% \mathrm{~N}_{2}$ (figura 4.8c), ocorre uma mudança marcante na morfologia superficial que se refere ao fato dos aglomerados de fósforo $\left(\mathrm{P}^{\circ}\right)$ deixarem de ser visíveis enquanto que os grãos que compõem o fundo original na imagem da figura $4.8 \mathrm{a}$ não mudam substancialmente de tamanho ficando ainda uma distribuição bimodal formada por

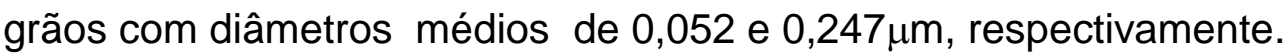


Estas observações baseadas na comparação entre as figuras $4.8 \mathrm{a}$ e $4.8 \mathrm{c}$ podem ser interpretadas e entendidas baseado no fato de que os aglomerados de fósforo em estado de oxidação zero $\left(\mathrm{P}^{\circ}\right)$ devem estar reagindo rapidamente na temperatura de $100^{\circ} \mathrm{C}$ com o oxigênio do ambiente da mistura $20 \% \mathrm{O}_{2}+80 \% \mathrm{~N}_{2}$ para formar óxido de fósforo $\left(4 \mathrm{P}^{\circ}+5 \mathrm{O}_{2}=\mathrm{P}_{4} \mathrm{O}_{10}\right)$ ao longo tanto da superfície do filme como nos interstícios dos grãos a ponto de impedir o aumento substancial do tamanho dos grãos já existentes e o aparecimento das fissuras observadas na figura 4.8b. Por outro lado, o recozimento na temperatura de $100^{\circ} \mathrm{C}$ em $\mathrm{N}_{2}$ ultrapuro, como já mencionado, não promove o desaparecimento dos aglomerados de fósforo que chegam até a aumentar ligeiramente de tamanho e passa a ocorrer o craqueamento do filme na forma de fissuras as quais devem estar sendo induzidas pelo aumento da tensão mecânica durante um processo de coalescência conforme sugere a figura 4.8b onde, como já mencionado, além das fissuras observam-se "plaquetas" não circulares com grão coalescidos com tamanhos variando na faixa de cerca de de 0,2 e $0,5 \mu \mathrm{m}$. Esse fato corrobora o que foi observado na figura $4.8 \mathrm{c}$, isto é, quando o recozimento passa a ser feito em ambiente de oxigênio, o rápido crescimento de óxido de fósforo $\left(\mathrm{P}_{4} \mathrm{O}_{10}\right)$ deve estar impedindo o efeito de craqueamento do filme.

A figura 4.10 mostra as imagens FE-SEM das ligas $\mathrm{Cu}-\mathrm{Ni}-\mathrm{P}$ recozidas a $100^{\circ} \mathrm{C}$ durante 10 min em ambiente de $20 \% \mathrm{O}_{2}+80 \% \mathrm{~N}_{2}$ para tempos de deposição de 1, 3, 5 e 7min, respectivamente. É importante destacar que os aglomerados de fósforo em estado de oxidação zero $\left(\mathrm{P}^{\circ}\right)$ não aparecem para nenhum caso de tempo de deposição. Para verificar, se ocorreu alguma mudança na estequiometria dos filmes, os mesmos foram novamente analisados por RBS após a etapa de recozimento a fim de extrair as porcentagens de níquel, cobre e fósforo. 
Figura 4.10 - Imagem FE-SEM das ligas Cu-Ni-P recozidas a $100^{\circ} \mathrm{C}$ em $20 \% \mathrm{O}_{2}+80 \% \mathrm{~N}_{2}$ durante $10 \mathrm{~min}$ para tempos de deposição de: (a) $1 \mathrm{~min}$, (b) $3 \mathrm{~min}$, (c) $5 \mathrm{~min}$ and (d) $7 \mathrm{~min}$.

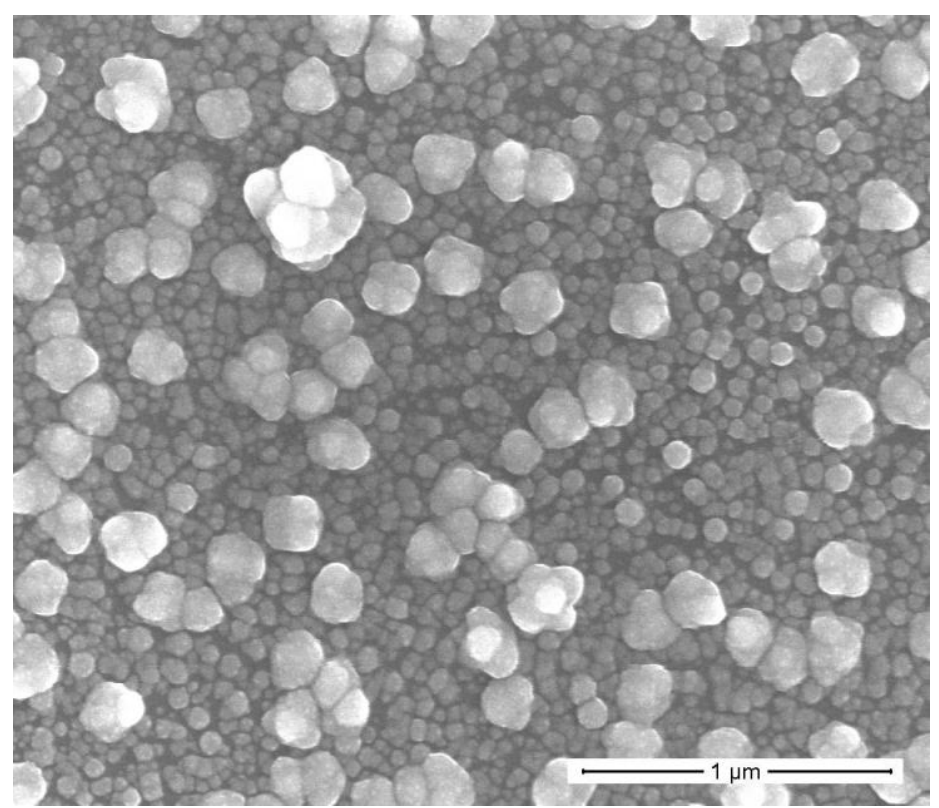

(a)

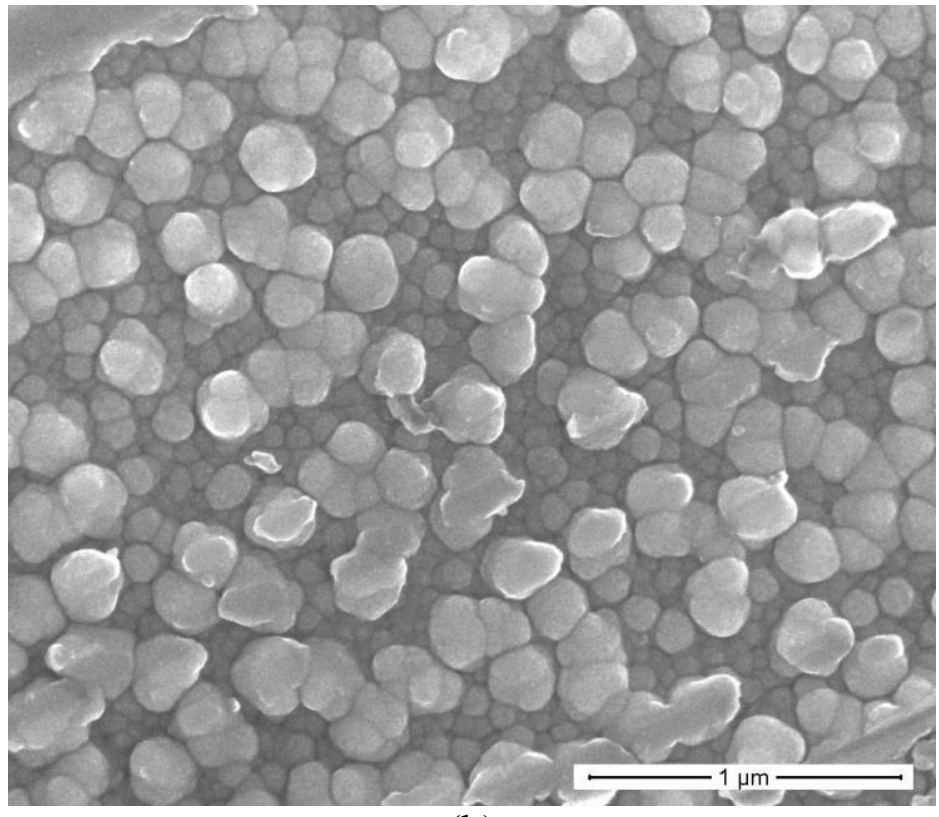

(b)

(continua na próxima página) 


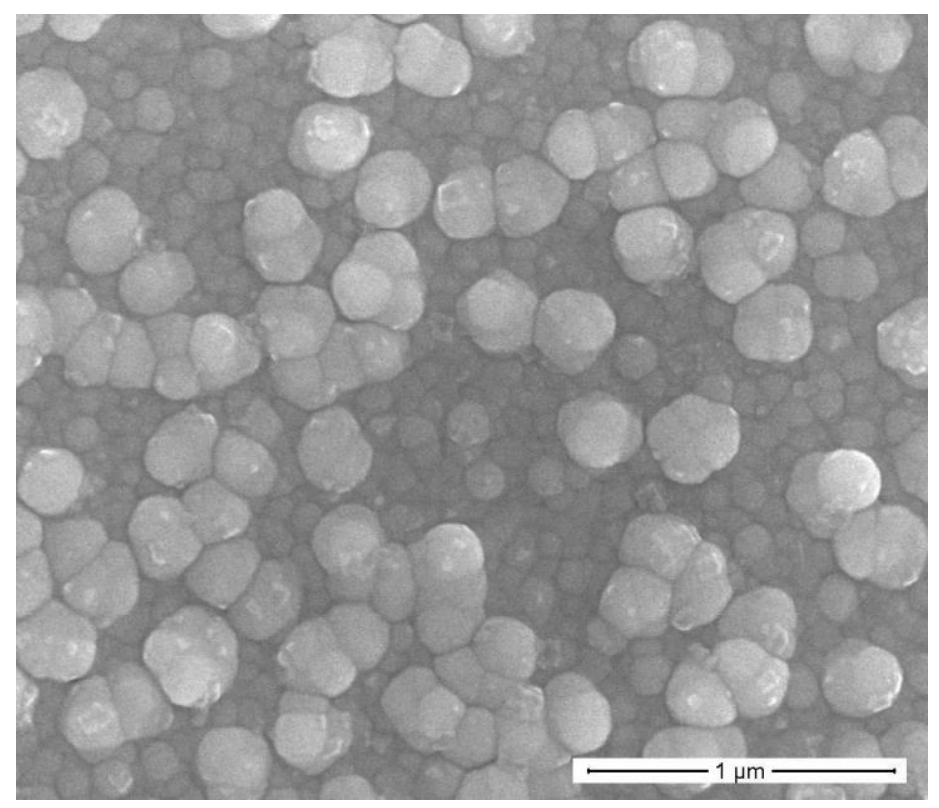

(c)

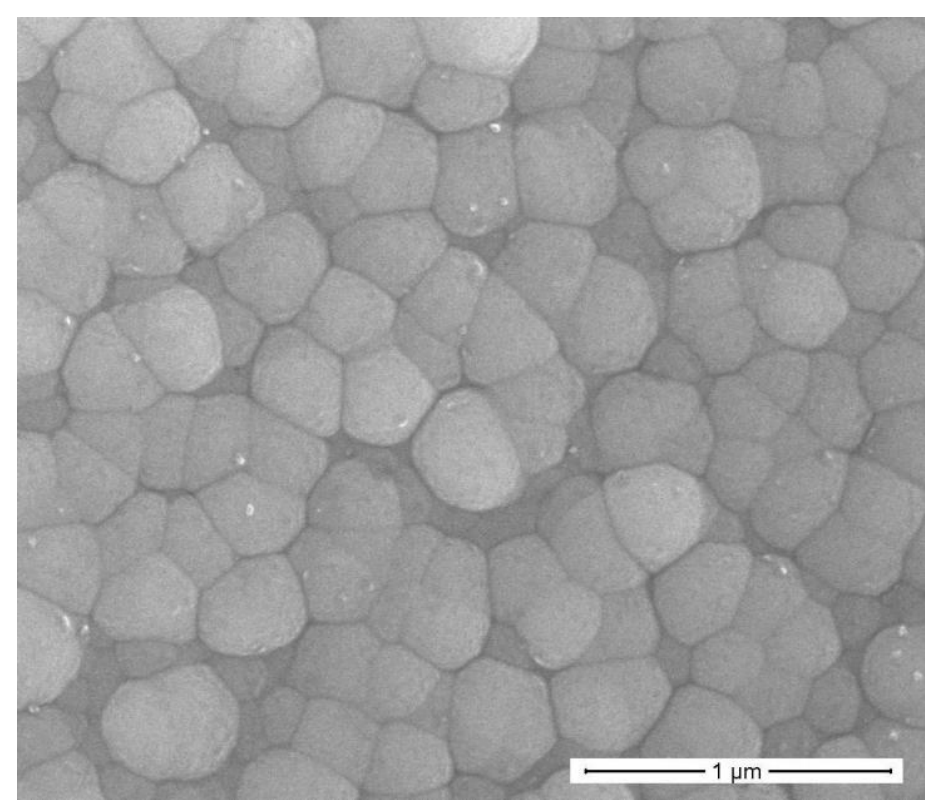

(d)

Fonte: Autor

A figura 4.11 mostra o espectro de RBS típico para uma liga Cu-Ni-P depositada durante $2 \mathrm{~min}$ e recozida a $100^{\circ} \mathrm{C}$ durante $10 \mathrm{~min}$ em ambiente $20 \% \mathrm{O}_{2}+80 \% \mathrm{~N}_{2}$. Observa-se nesta figura que apesar não haver aglomerados de fósforo em estado de oxidação zero na superfície das amostras recozidas $\left(\mathrm{P}^{\circ}\right)$, existe ainda a presença de átomos de fósforo no filme conforme atesta a figura 4.11 
a seguir. A partir das simulação utilizando o programa SiMNRA (MAYER, 1999), a concentração de fósforo foi extraída e ainda apresenta valor semelhante ao valor de antes do recozimento ( $17-18 \%)$ o que significa que o fósforo ainda está presente no filme.

Figura 4.11 - Espectro de RBS típico e simulação para o tempo de imersão de $2 \mathrm{~min}$ e após recozimento a $100^{\circ} \mathrm{C} \mathrm{em}$ ambiente $20 \% \mathrm{O}_{2}+80 \% \mathrm{~N}_{2}$.

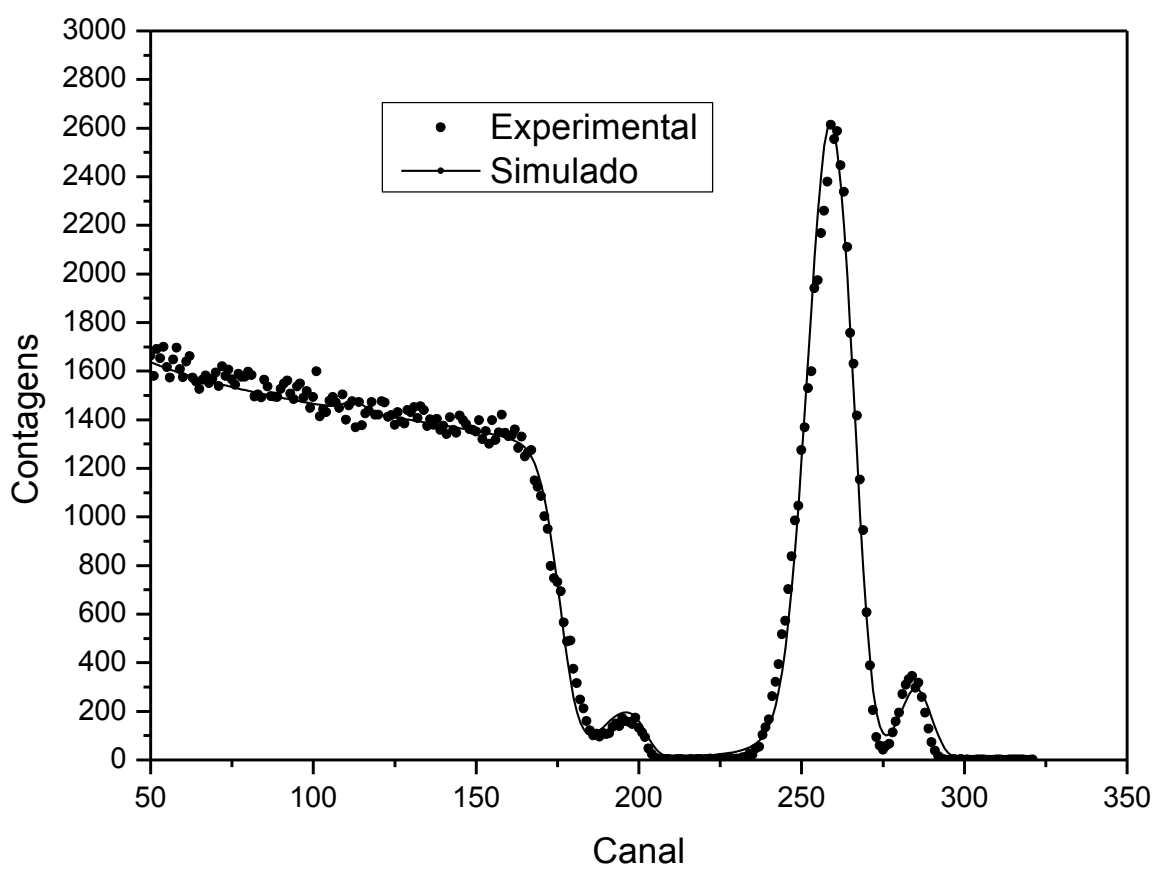

Fonte: Autor

A figura 4.12 ilustra a porcentagem estequiométrica de $\mathrm{Ni}$, Cu e $\mathrm{P}$ como uma função do tempo de deposição obtida a partir das análises RBS realizadas para os diversos tempos de deposição empregados (1, 2, 3, 5, 7 e 10min). Os resultados obtidos após o recozimento (figura 4.12) foram similares àqueles obtidos para a situação sem recozimento (figura 4.3) dentro da incerteza representada pelas barras de erro dos pontos experimentais extraídos através da técnica RBS. Foi observado que as porcentagens estequiométricas de $\mathrm{Ni}$ e $\mathrm{Cu}$ após o recozimento tiveram o mesmo comportamento que para o caso sem recozimento, isto é, elas variaram 
substancialmente nos tempos de imersão entre 1 e 3min e ficaram estáveis em torno de $50 \%$ e $35 \%$, respectivamente, quando o tempo de imersão foi maior do que $3 \mathrm{~min}$. A porcentagem de $\mathrm{P}$ permaneceu na faixa de 17 a $18 \%$ para a faixa de tempos de deposição considerada.

Figura 4.12 - - Porcentagens estequiométricas de $\mathrm{Ni}$, $\mathrm{Cu}$ e $\mathrm{P}$ como uma função do tempo de imersão para amostras recozidas a $100^{\circ} \mathrm{C}$ durante $10 \mathrm{~min}$ em ambiente de $20 \% \mathrm{O}_{2}+80 \% \mathrm{~N}_{2}$.

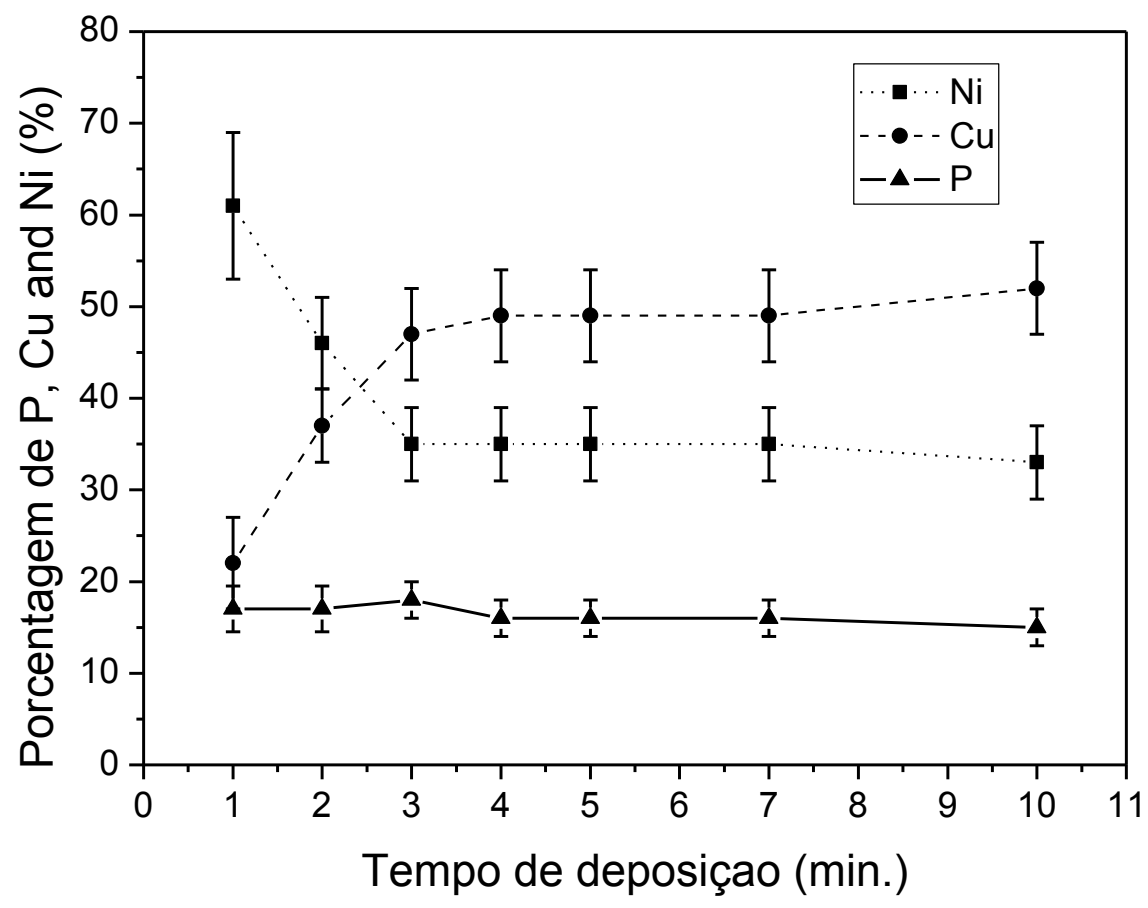

Fonte: Autor

A figura 4.13 mostra as análises de difração de raios X (XRD) extraída para os tempos de 1, 2, 5 e $10 \mathrm{~min}$ após o recozimento realizado a $100^{\circ} \mathrm{C}$ por $10 \mathrm{~min}$ em ambiente de $20 \% \mathrm{O}_{2}+80 \% \mathrm{~N}_{2}$. Em todos os casos, verificou-se o aparecimento de um pico de difração alargado ao redor de 22,6 característico de óxido de fósforo $\left(\mathrm{P}_{2} \mathrm{O}_{5}\right)$ com estrutura vítrea amorfa (SOHEYLI, 2016; SIDDIQUI, 2013; HOPPE, 2014) e picos substancialmente menos intensos indicando a presença de pequenas quantidades de $\mathrm{NiO}, \mathrm{Ni}_{3} \mathrm{P}$ e $\mathrm{Si}_{5} \mathrm{P}_{6} \mathrm{O}_{25}$. Portanto, considerando que as aglomerações de fósforo em estado puro $\left(\mathrm{P}^{0}\right)$ desapareceram após o recozimento conforme 
mostrado na figura 4.10 e baseado nos picos de difração intensos apontando para a formação de $\mathrm{P}_{2} \mathrm{O}_{5}$, concluímos que o fósforo em estado puro foi transformado na sua forma oxidada e amorfa. É interessante observar que o pico de $\mathrm{P}_{2} \mathrm{O}_{5}$ resultou mais intenso para os filmes mais espessos com tendência de diminuição (de área) para o tempo de 10min possivelmente porque começou a diminuir a quantidade de fósforo incorporado para 10min como sugere a figura 4.12 dentro do erro experimental.

Figura 4.13 - Medidas XRD das ligas Cu-Ni-P para os tempos de deposição indicados dentro da figura e recozidos a $100^{\circ} \mathrm{C} \mathrm{em} 20 \% \mathrm{O}_{2}+80 \% \mathrm{~N}_{2}$.

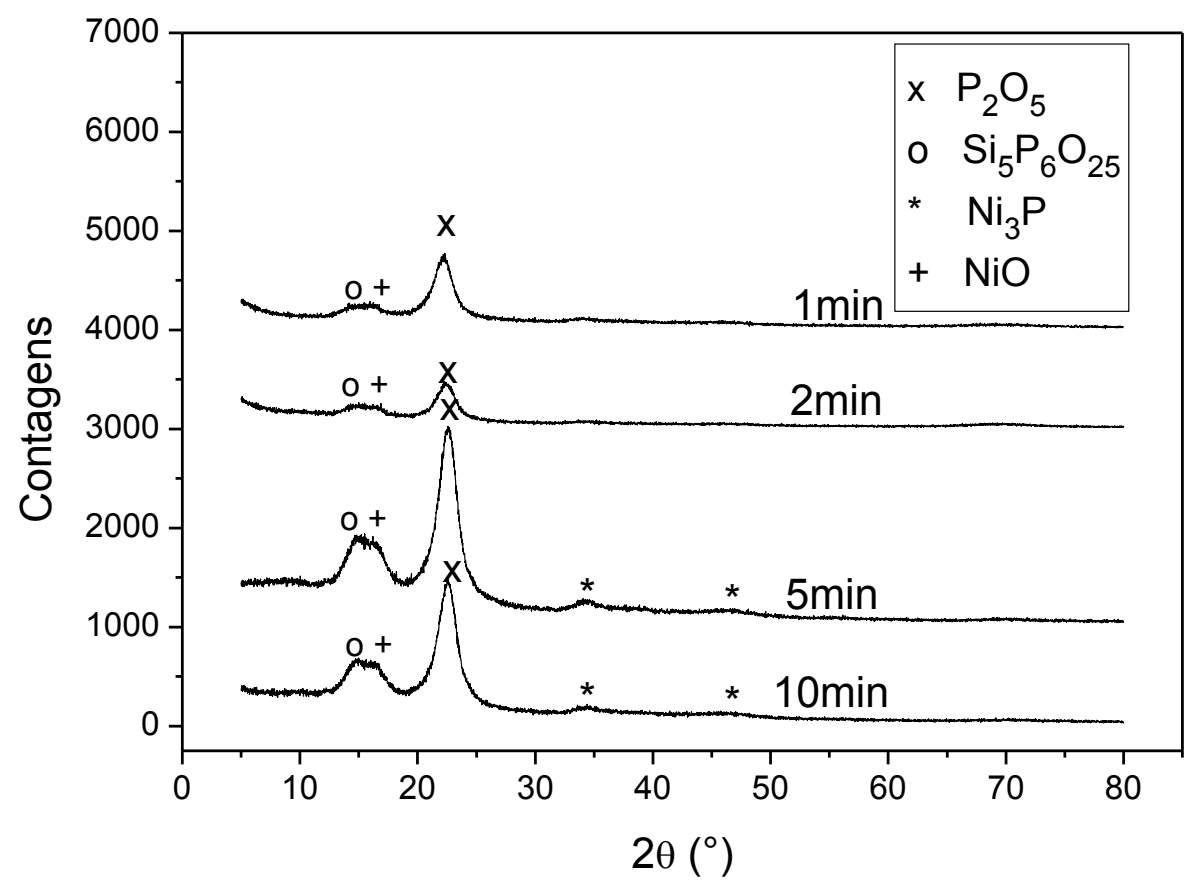

Fonte: Autor

A figura 4.14 mostra o comportamento da resistividade como função do tempo de deposição para as ligas Cu-Ni-P não recozidas e recozidas a $100^{\circ} \mathrm{C}$ por $10 \mathrm{~min}$ em ambiente de $20 \% \mathrm{O}_{2}+80 \% \mathrm{~N}_{2}$, respectivamente. Da comparação das duas curvas, verificou-se para os filmes recozidos que a resistividade obtida foi maior para praticamente todos os tempos de deposição incluindo todos os tempos maiores do que 3min. Além disso, as barras de erro correspondendo ao desvio padrão em 
conjuntos de 10 pontos medidos para cada tempo de deposição resultou substancialmente maior para as amostras recozidas. Esses dois fatos, isto é, a maior resistividade e o maior desvio padrão para os filmes recozidos podem ser explicados pela formação de $\mathrm{P}_{2} \mathrm{O}_{5}$ na superfície que deve ter dificultado a medida da resistência de folha pelo método de quatro pontos já que o $\mathrm{P}_{2} \mathrm{O}_{5}$ formado apresenta estrutura amorfa e menor condutividade face ao cobre e o níquel (SOHEYLI, 2016). Essa maior dificuldade de medida deve ter promovido inclusive maior dispersão dos resultados, ou seja, resistências de contato aleatórias das quatro pontas sobre a superfícies dos filmes recobertos com $\mathrm{P}_{2} \mathrm{O}_{5}$.

Figura 4.14 - Resistividade como uma função do tempo de deposição para ligas Cu-Ni-P não recozidas (logo que depositadas) e recozidas a $100^{\circ} \mathrm{C}$ por $10 \mathrm{~min}$ em ambiente de $20 \% \mathrm{O}_{2}+80 \% \mathrm{~N}_{2}$, respectivamente.

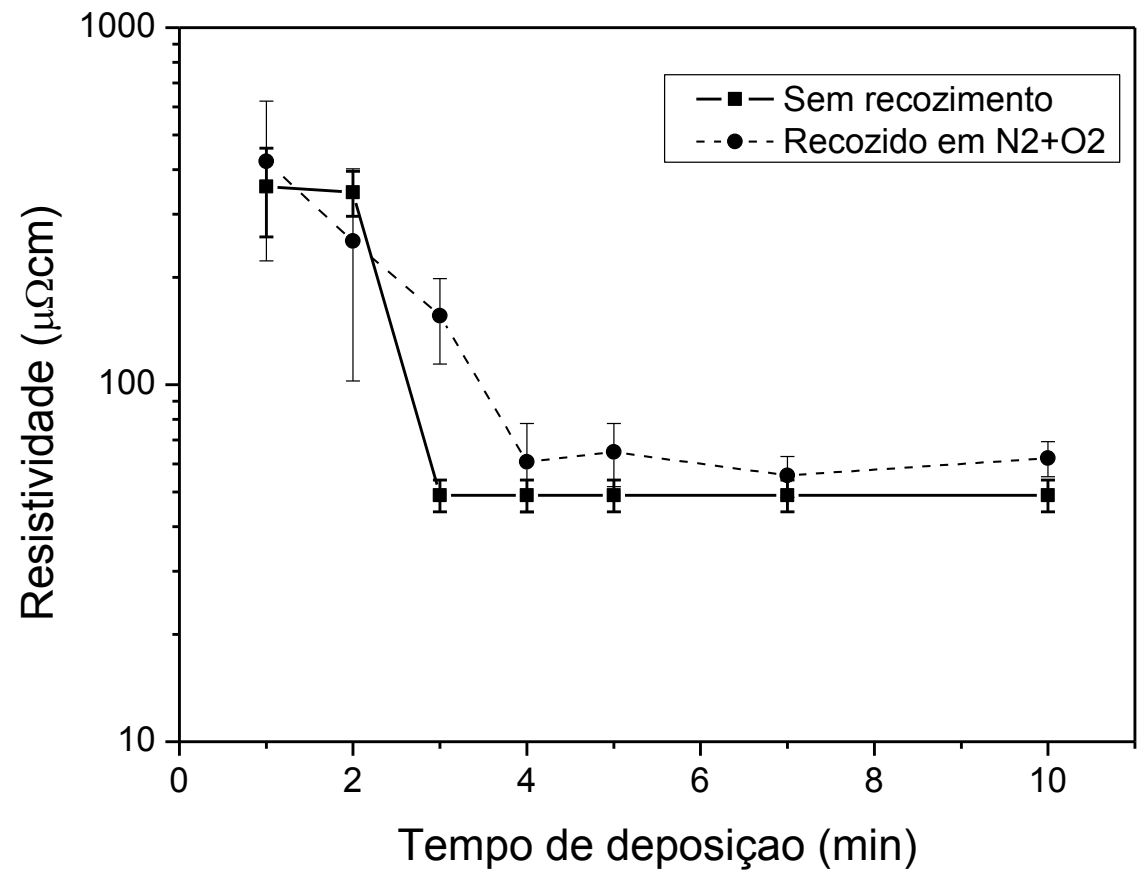

Fonte: Autor 


\subsection{Caracterização do poder termoelétrico de filmes de Cu-Ni-P}

No capítulo 3 sobre procedimentos experimentais foi apresentada a montagem experimental empregada para a medida do poder termoelétrico (figura 3.1) dos filmes de Cu-Ni-P para os tempos de deposição na faixa de 1 a 10min empregados neste trabalho. A figura 4.15 mostra o poder termoelétrico medido em função da temperatura para ligas Cu-Ni-P depositadas por 3min nas situações sem recozimento e com recozimento a $100^{\circ} \mathrm{C}$ por 10 min em ambiente $20 \% \mathrm{O}_{2}+80 \% \mathrm{~N}_{2}$, respectivamente. É interessante observar para os filmes não recozidos com aproximadamente $300 \mathrm{~nm}$ de espessura que o poder termoelétrico variou na faixa de $-77 \mu \mathrm{V} /{ }^{\circ} \mathrm{C}$ a $-50 \mu \mathrm{V} /{ }^{\circ} \mathrm{C}$ para temperatura de operação variando na faixa de 40 a $120^{\circ} \mathrm{C}$ de forma não linear já que poder termoelétrico salta de $-77 \mu \mathrm{V} /{ }^{\circ} \mathrm{C}$ para $-60 \mu \mathrm{V} /{ }^{\circ} \mathrm{C}$ quando a temperatura varia apenas de 40 a $60^{\circ} \mathrm{C}$. Essa faixa de valores do poder termoelétrico medido tem sido observada para filmes finos de CuNi puros para espessuras em torno de 300nm (DELATORRE, 2003). No entanto, a variação do poder termoelétrico nessa faixa de temperatura é linear nos filmes de CuNi da literatura o que é adequado na aplicação da liga para a fabricação de termopares CuNi/Cu (DELATORRE, 2003). No nosso caso, a variação não linear do poder termoelétrico acaba inviabilizando sua aplicação em termopares.

Por outro lado, os filmes recozidos a $100^{\circ} \mathrm{C}$ por $10 \mathrm{~min}$ em ambiente de $20 \% \mathrm{O}_{2}+80 \% \mathrm{~N}_{2}$ apresentaram o poder termoelétrico na faixa de $-40 \mu \mathrm{V} /{ }^{\circ} \mathrm{C}$ a $-45 \mu \mathrm{V} /{ }^{\circ} \mathrm{C}$ para temperatura de operação variando na faixa de 40 a $120^{\circ} \mathrm{C}$ de forma linear e reprodutível. Isso significa que apesar do poder teremoelétrico ser ligeiramente menor comparado ao caso não recozido, o comportamento linear e reprodutível permite a sua utilização na fabricação de termopares. 
Figura 4.15 - Poder termoelétrico como função da temperatura para ligas Cu-Ni-P depositadas por $3 \mathrm{~min}$ sem recozimento e recozidas a $100^{\circ} \mathrm{C}$ por $10 \mathrm{~min}$ em $20 \% \mathrm{O}_{2}+80 \% \mathrm{~N}_{2}$, respectivamente.

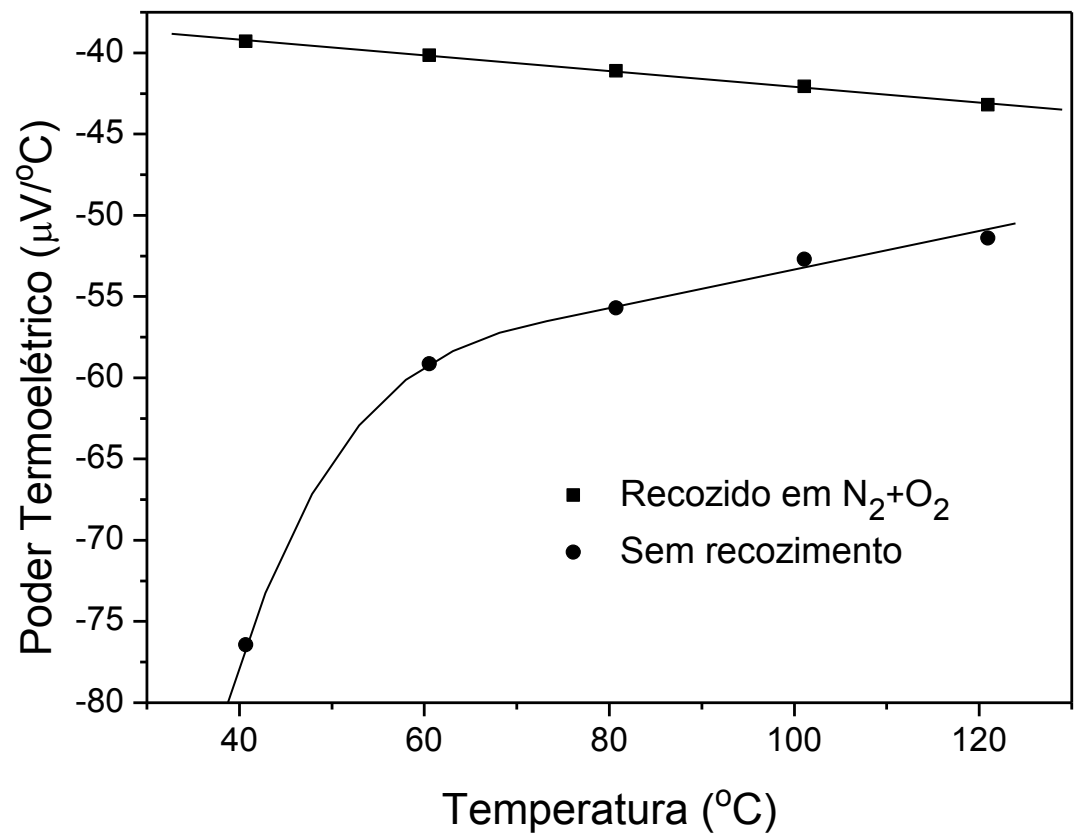

Fonte: Autor

A figura 4.16, por sua vez, mostra o poder termoelétrico de ligas Cu-Ni-P recozidas a $100^{\circ} \mathrm{C}$ por $10 \mathrm{~min}$ em ambiente de $20 \% \mathrm{O}_{2}+80 \% \mathrm{~N}_{2}$ como função do tempo de deposição parametrizada na temperatura de medida. É importante observar que o comportamento do poder termoelétrico é quase independente do tempo de deposição e, portanto, da espessura do filme para as diversas temperaturas medidas. Esse comportamento quase independente da espessura e o comportamento linear com a temperatura já comentado, confere às ligas $\mathrm{Cu}-\mathrm{Ni}-\mathrm{P}$ recozidas em baixa temperatura em ambiente $20 \% \mathrm{O}_{2}+80 \% \mathrm{~N}_{2}$ características muito boas para o seu emprego na fabricação de termopares $\mathrm{Cu} / \mathrm{Cu}-\mathrm{Ni}-\mathrm{P}$. 
Figura 4.16 - Poder termoelétrico de ligas Cu-Ni-P recozidas a $100^{\circ} \mathrm{C}$ por $10 \mathrm{~min}$ em ambiente de $20 \% \mathrm{O}_{2}+80 \% \mathrm{~N}_{2}$ como função do tempo de deposição para diversas temperaturas de medida.

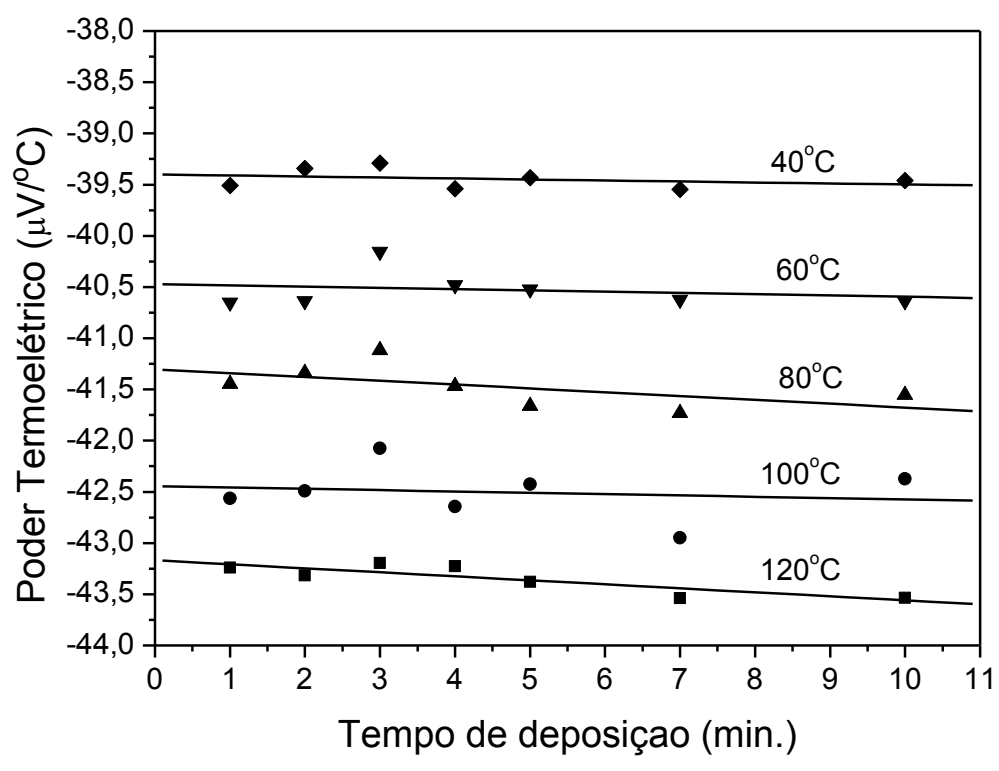

Fonte: Autor

O comportamento muito bom obtido para o caso dos filmes recozidos em baixa temperatura em ambiente $20 \% \mathrm{O}_{2}+80 \% \mathrm{~N}_{2}$ pode ser atribuído à formação do óxido de fósforo $\left(\mathrm{P}_{2} \mathrm{O}_{5}\right)$. Nesse caso o óxido de fósforo deve estar recobrindo todos os grãos do filme de Cu-Ni-P, inclusive os interstícios, a ponto de conferir um comportamento do poder termoelétrico quase independente da temperatura e da espessura assim como observado para óxidos de fósforo vítreos com íons metálicos $\left(\mathrm{MO}_{\mathrm{x}}-\mathrm{P}_{2} \mathrm{O}_{5}\right)$ (TAWATI, 2004; MANSINGH, 1978).

Além da comparação feita entre os casos com e sem oxidação do fósforo na figura 4.15, é importante destacar que os valores de poder termoelétrico obtidos na figura 4.16 na faixa de $-39,5 \mu \mathrm{V} /{ }^{\circ} \mathrm{C}$ a $-44,5 \mu \mathrm{V} /{ }^{\circ} \mathrm{C}$ para patamares de temperatura na faixa de 40 a $120^{\circ} \mathrm{C}$ é consistente com ligas $\mathrm{NiO}-\mathrm{P}_{2} \mathrm{O}_{5}$ com baixo conteúdo de $\mathrm{Ni}$ obtidas pelo processo "Melting" (TAWATI, 2004) onde o poder termoelétrico ficou na faixa de $-62 \mu \mathrm{V} /{ }^{\circ} \mathrm{C}$ a $-65 \mu \mathrm{V} /{ }^{\circ} \mathrm{C}$ para os mesmos patamares de temperatura. 


\section{Conclusões e Perspectivas Futuras}

Filmes finos de Cu-Ni-P foram quimicamente depositados usando um banho químico contendo $15 \mathrm{~g} / / \mathrm{NiSO}_{4} \cdot 6 \mathrm{H}_{2} \mathrm{O} ; 0,2 \mathrm{~g} / \mathrm{l} \mathrm{CuSO}_{4} \cdot 5 \mathrm{H}_{2} \mathrm{O} ; 15 \mathrm{~g} / \mathrm{l} \mathrm{Na}{ }_{2} \mathrm{HPO}_{2} \cdot \mathrm{H}_{2} \mathrm{O}$ e 60 g/l $\mathrm{Na}_{3} \mathrm{C}_{6} \mathrm{H}_{5} \mathrm{O}_{7} \cdot 2 \mathrm{H}_{2} \mathrm{O}$ mantido na temperatura de $80^{\circ} \mathrm{C}$ onde $\mathrm{NH}_{4} \mathrm{OH}$ foi adicionado até que $\mathrm{opH}$ atingisse 8,0. A estequiometria dos filmes foram obtidas com a ajuda da técnica Espectrometria de Retroespalhamento de Rutherford (RBS) e a morfologia de superfície foi caracterizada através de um Microscópio Eletrônico de Varredura (SEM).

Foi observado que o cobre deposita preferencialmente na superfície devido ao seu elevado potencial de redução em relação ao níquel e o fósforo. Assim, foi estabelecido uma razão atômica de Ni/Cu de pelo menos 70 na solução química para a obtenção da razão de 0,5 de Ni/Cu no depósito.

Foi também observado que as porcentagens estequiométricas de $\mathrm{Ni}$ e $\mathrm{Cu}$ variaram substancialmente para tempos de deposição no intervalo de 1 a $3 \mathrm{~min}$, ficando praticamente estável em 50\% e 35\%, respectivamente, quando o tempo de deposição foi superior a 3min. Além disso, a porcentagem de $P$ permaneceu quase constante em torno de $17-18 \%$ para toda a faixa de tempos de deposição empregadas. Por outro lado, a resistência de folha também variou substancialmente para tempos de deposição na faixa de 1 a 3 min.

Para tempos de deposição na faixa de 1 a 3 min, foi observada uma correlação direta entre o tipo de morfologia superficial e as porcentagens de $\mathrm{Ni}$ e $\mathrm{Cu}$

obtidas. É importante destacar que a distribuição de alturas nas imagens FE-SEM resultou bimodal para os tempos de 1 e 3 min onde a predominância do modo de maior altura aumenta substancialmente para o tempo de $3 \mathrm{~min}$. Tal fato corroborou quantitativamente a mudança da morfologia superficial de grãos menores com 
diâmetros na faixa de 0,02 a $0,1 \mu \mathrm{m}$, predominantemente compostos de $\mathrm{Ni}$, para grãos maiores na faixa de 0,1 a $0,3 \mu \mathrm{m}$, predominantemente compostos de $\mathrm{Cu}$. Por outro lado, para o tempo de 7min, uma distribuição de alturas monomodal foi observada para uma superfície completamente fechada com os grãos maiores de cerca de $0,3 \mu \mathrm{m}$ na média com um comcomitante aumento de espessura (valor médio da altura próximo a 70nm).

Após o recozimento a $100^{\circ} \mathrm{C}$ durante $10 \mathrm{~min}$ em $\mathrm{N}_{2}$ ultrapuro, os grãos coalesceram em algum grau e começam a aparecer fissuras e rachaduras, possivelmente devido ao efeito de tensionamento mecânico proveniente em parte da tendência de coalescência. Observou-se na superfície "plaquetas" não circulares com grão coalescidos com tamanhos variando na faixa de cerca de 0,2 e $0,5 \mu m$ e grãos claros associados a aglomerados de fósforo $\left(\mathrm{P}^{\circ}\right)$ com diâmetro médio um pouco maior do que $0,032 \mu \mathrm{m}$ comparado ao caso sem recozimento.

Após o recozimento a $100^{\circ} \mathrm{C}$ durante $10 \mathrm{~min}$ em ambiente $20 \% \mathrm{O}_{2}+80 \% \mathrm{~N}_{2}$, observou-se uma mudança marcante na morfologia superficial associado ao fato dos aglomerados de fósforo $\left(\mathrm{P}^{0}\right)$ desaparecerem enquanto os grãos que compõem o fundo original não mudam substancialmente de tamanho ficando ainda uma distribuição bimodal formada por grãos com diâmetros médios de 0,052 e 0,247 $\mu$ m, respectivamente. Apesar do desaparecimento dos aglomerados de de fósforo $\left(\mathrm{P}^{\circ}\right)$, a concentração de fósforo ainda apresentou valor semelhante ao valor de antes do recozimento ( 17-18\%) o que significa que o fósforo ainda está presente no filme, de acordo com as análises de RBS.

As análises de difração de raios $\mathrm{X}(\mathrm{XRD})$ foram extraídas para amostras com tempos de deposição na faixa de 1 a 10 min e recozimento realizado a $100^{\circ} \mathrm{C}$ por $10 \mathrm{~min}$ em ambiente de $20 \% \mathrm{O}_{2}+80 \% \mathrm{~N}_{2}$. Em todos os casos, verificou-se o 
aparecimento de um pico de difração alargado ao redor de 22,6 ำ característico de óxido de fósforo $\left(\mathrm{P}_{2} \mathrm{O}_{5}\right)$ com estrutura vítrea amorfa e picos substancialmente menos intensos indicando a presença de pequenas quantidades de $\mathrm{NiO}, \mathrm{Ni}_{3} \mathrm{P}$ e $\mathrm{Si}_{5} \mathrm{P}_{6} \mathrm{O}_{25}$. Portanto, concluímos que o fósforo em estado puro foi transformado na sua forma oxidada. É interessante observar que o pico de $\mathrm{P}_{2} \mathrm{O}_{5}$ resultou mais intenso para os filmes mais espessos com tendência de diminuição para o tempo de 10min possivelmente porque começou a diminuir a quantidade de fósforo incorporado.

A partir dos gráficos de resistividade como função do tempo de deposição para as ligas Cu-Ni-P não recozidas e recozidas a $100^{\circ} \mathrm{C}$ por $10 \mathrm{~min}$ em ambiente de $20 \% \mathrm{O}_{2}+80 \% \mathrm{~N}_{2}$, verificou-se para os filmes recozidos que a resistividade obtida foi maior para praticamente todos os tempos de deposição. Além disso, as barras de erro correspondendo ao desvio padrão em conjuntos de 10 pontos medidos para cada tempo de deposição resultou substancialmente maior para as amostras recozidas. Esses dois fatos podem ser explicados pela formação de $\mathrm{P}_{2} \mathrm{O}_{5}$ na superfície que deve ter dificultado a medida da resistência de folha pelo método de quatro pontos já que o $\mathrm{P}_{2} \mathrm{O}_{5}$ formado apresentou estrutura vítrea amorfa evidenciada pelo aparecimento de um pico de difração alargado ao redor de $22,6^{0}$ característico de óxido de fósforo $\left(\mathrm{P}_{2} \mathrm{O}_{5}\right)$ (SOHEYLI, 2016; SIDDIQUI, 2013; HOPPE, 2014)

Finalmente, o poder termoelétrico medido resultou quase independente do tempo de deposição e, portanto, da espessura do filme para as diversas temperaturas medidas. Esse comportamento quase independente da espessura e o comportamento linear com a temperatura confere às ligas $\mathrm{Cu}-\mathrm{Ni}-\mathrm{P}$ recozidas em baixa temperatura em ambiente $20 \% \mathrm{O}_{2}+80 \% \mathrm{~N}_{2}$ características muito boas para 0 seu emprego na fabricação de termopares $\mathrm{Cu} / \mathrm{Cu}$-Ni-P. Além disso, é importante também destacar que o poder termoelétrico foi medido na faixa de $-39,5 \mu \mathrm{V} /{ }^{\circ} \mathrm{C}$ 
a $-44,5 \mu \mathrm{V} /{ }^{\circ} \mathrm{C}$ para patamares de temperatura na faixa de 40 a $120^{\circ} \mathrm{C}$ e é consistente com ligas $\mathrm{NiO}-\mathrm{P}_{2} \mathrm{O}_{5}$ com baixo conteúdo de $\mathrm{Ni}$ obtidas pelo processo "Melting" (TAWATI, 2004) onde o poder termoelétrico ficou na faixa de $-62 \mu \mathrm{V} /{ }^{\circ} \mathrm{C}$ a $-65 \mu \mathrm{V} /{ }^{\circ} \mathrm{C}$ para os mesmos patamares de temperatura.

Como perspectivas futuras para a continuação do presente trabalho, podemos destacar:

a) Análise da morfologia superficial para outros valores de concentração de fósforo incorporados no filme de Cu-Ni-P.

b) Análise da influência da temperatura na formação de $\mathrm{P}_{2} \mathrm{O}_{5}, \mathrm{NiO}$ e $\mathrm{CuO}$.

c) Análise da influência das quantidades formadas de $\mathrm{NiO}$ e $\mathrm{CuO}$ no valor do poder termoelétrico medido. 


\section{Referências Bibliográficas}

AVERBUCH-POUCHOUT, M-T.; DURIF, A. Topics in phosphate chemistry, World Scientific, p. 3, 1996.

BAJZEK, T. J. Thermocouple: a sensor for measuring temperature. IE EEInstrumentation \& Measurement Magazine. New York: Institute of Electrical and Electronics Engineers, 1973-, p. 35 - 40, mar. 2005.

BARKER, D. Electroless deposition of metals. AIFM Galvano Técnica e Nuove Finiture. v. 16, n.4, p. 216-218, 220, 222-224, 226-228. set.- out. 2006.

BATES, J. Why use electroless nickel today. Plating and Surface Finishing. v. 85, n. 5, p. 74-78, mai. 1998.

BLATT, F.J.; SCHROEDER, P.A.; FOILES, C.L.; GREIG, D. Thermoelectric Power of Metals, Plenum, New York, 1976, p. 5.

BRENNER, A.; RIDDEL, G. A model for hipophosphite reduction in electroless nickel plating. Journal Res. Nat. Bur., v. 37, p. $31-39,1946 a$.

BRENNER, A.; GRACE, E.J. Proc. Am. Electroplaters' Soc. v. 33, p. 16, 1946.

BRENNER, A.; GRACE, E.J. Proc. Am. Electroplaters' Soc. v. 34, p. 156, 1947.

BYEON, J. H. et al. Electroless copper deposition on a pitch-based active carbon fiber and an application for n.o. removal. Surface and Coatings Technology. v. 202 , p. 3571 - 3578, abr.2008.

CHATTAWAY, F. D. Procedures R. Society. 80A, p. 88-92, fev. 1908. 
CHEN,C.; LIN,K. The deposition and crystallization behaviors ofelectroless ni-cu-p deposits. Journal of the Electrochemical Society. n. 146, p. 137 -140, 1999.

CHU, W. et al. Backscattering spectrometry. ed. Academic Press, 1978. DALLY, J. W.; RILEY, W. F. E.; MCCONNELL, K. G. Instrumentation for engineering measurements. ed. Wiley, p. 456 - 459, 1993.

DELATORRE, R. G. et al. Thermoelectric properties of electrodeposited CuNi alloys on Si. Journal of Applied Physics. v. 93, n. 10, p. 6154 - 6158, 2003.

DUBIN, V.M. Selective electroless $\mathrm{Ni}-\mathrm{Cu}(\mathrm{P})$ deposition for via hole filling and conductor pattern cladding in VLSI multilevel interconnection structures. J. Electrochem. Soc., v. 139, n. 2, 1992.

ECHLINE, P., Handbook of Sample Preparation for Scanning Electron Microscopy and X-ray Microanalysis. 2010, New York: Springer. 330.

GARDNER, J. W. Microsensors - Principles and applications. ed. Jonh Wiley \& Sons LTD, p. 83, 1994.

GEORGIEVA, J.; ARMYANOV, S. Electroless deposition and some properties of $\mathrm{Ni}-$ $\mathrm{Cu}-\mathrm{P}$ and Ni-Sn-P coatings. Journal of Solid State Electrochemistry. v. 11, n. 7, jul. 2007.

GLATZ, W.; HIEROLD, C. Flexible micro thermoelectric generator. Micro Electro Mechanical Systems. Hyogo: IEE 20тн Internacional Conference, 2007.

GOLDSTEIN, J., et al., Scanning Electron Microscopy and X-ray Microanalysis. Third ed. 2003, New York: Springer.

HENRI, P. H.; THERY, P. Measurement science technology. v. 3, p. 495, 1992 
GUTZEIT, G. A model for hypophosphite reaction. Plating. v. 46, p. $1158-1165$, 1959.

HONG, S. W. et al. Nucleation and growth of electroless palladium deposition on polycrystalline tin barrier films for electroless copper deposition. Journal of the Electrochemical Society. v. 150, n. 1, p. C16 - 18, 2003.

HOPPE, H.; WALTER, G.; KRANOLD, R.; STACHEL, D. An X-ray diffraction study of the structure of vitreous $\mathrm{P}_{2} \mathrm{O}_{5}$. Verlag der Zeitschrift für Naturforschung $\mathbf{A}, \mathrm{v}$. 53(3-4), p. 93-104, 2014.

HUNG, A.; OHNO, I. Electrochemical study of hypophosphite-reduced electroless copper deposition. Journal of the Electrochemical Society. v.137, n. 3, p. 918 $921,1990$.

HWANG, B.J.; LIN, S.H. Reaction mechanism of electroless depostion: observations of morphology evolution during nucleation and growth via tapping mode AFM. J. Electrochem. Soc. v. 142, n. 11, p. 3749, 1995.

JONES, D. A. Principles and prevention of corrosion. ed. Macmillian Publishing Company, 1992.

KERN, W.; PUOTINEN, D. A. RCA Rev., v. 31, p. 187, 1970.

LIN, K. L.; HWANG, J. W. Effect of crystallinity and thickness on the diffusion barrier behavior of electroless nickel deposit between $\mathrm{Cu}$ and solder. IEEE Transaction on Advanced Packaging. v. 25, n. 4, p. 509 - 513, 2002.

LUKES, R. M. Plating. v.51, p. 1066-1068, 1964.

MALLORY, G. O.; HADJU, J. B. Electroless plating: Fundamentals and applications. ed. AESF, 1990. 
MANSINGH, A.; DHAWAN, A. Thermoelectric power in transition metal oxide glasses. J. Phys. Solid State Phys., v. 11, p. 3439-3445, 1978.

MARQUES, A. E. B.; HASAN, N. M.; SANTOS FILHO, S. G. Ni electroless plating onto Pd-Actived silicon surfaces. In: Proceedings of the XIV International Conference on Microelectronics and Packaging, São Paulo, v. 1, p. 277-279, 1999.

MARQUES, A. E. B. et al. Physical and electrical characterization of thin nickel films obtained from electroless plating onto aluminum. Physical Status Solidi. n. 1, p. 75 - 84, 2001.

MARQUES, A. E. B.; SANTOS FILHO, S. G.; MARTINI, S. Electroless nickel deposition onto silicon surfaces for micro and nanoelectronics applications and microtechnology processes. Physica Status Solidi (C). v. 4, p. 256 - 258, fev. 2007.

MAYER, M. SIMNRA, a Simulation Program for the Analysis of NRA, RBS and ERDA. Proceedings of the 15th International Conference on the Application of Accelerators in Research and Industry (Denton, Texas, 1999) ed J L Duggan, I L Morgan (Maryland: American Institute of Physics, vol 475) p 541, 1999.

PARK, J.J.; TAYA, M. Micro-Temperature sensor array with thin-film thermocouples. Electronics Letters. v. 40, n. 10, 2004.

OABI, O.; MAAROUFI, A.; LUCAS, B.; EL AMRANI, A. Thermoelectric Properties of ZnO- $\mathrm{P}_{2} \mathrm{O}_{5} /(\mathrm{Ni})$ Composites. New Journal of Glass and Ceramics, v. 6, p. 19-27, 2016.

PARRA, F. T. S. Fabricação e Caracterização de Termopares $\mathrm{Cu} / \mathrm{Cu}-\mathrm{Ni}-\mathrm{P}$ Obtidos por Deposição Eletroquímica e Simulações Térmicas de Estruturas de Termopar para Radiometria. 2013. Tese (Doutorado) - Escola Politécnica, Universidade de São Paulo, São Paulo, 2013. 
RAMANANDAN, G.K.P.; RAMAKRISHNAN, G.; PLANKEN, P.C.M. Oxidation kinetics of nanoscale copper films studied by terahertz transmission spectroscopy, J. of Appl. Phys., v. 111, p. 123517, 2012.

REIMER, L., Scanning Electron Microscopy: Physics of Image Formation and Microanalysis. Springer Series in Optical Sciences, ed. H.K.V. Lotsch. Vol. 45. 1998, New York: Springer.

REKHA, K. et al. Electroless deposition of copper from methane sulphonate complexed bath. Transactions of the Institute of Metal Finishing. v. 88, n.4, p.215 $-219,2010$.

ROHAN, J. F.; O'RIORDAN, G. Characterization of the electroless nickel deposits as a barrier layer under bump metallurgy on ic metallization. Microelectronics Engineering. v. 65, p. 77-85, 2003.

SANTOS FILHO, S. G. dos Oxidação térmica rápida do silício: influência dos procedimentos de limpeza e dos perfis temporais de temperatura na qualidade dos óxidos de porta mos. 1996. Tese (Doutorado) - Escola Politécnica, Universidade de São Paulo, São Paulo, 1996.

SCHEPIS, R. et al. Influence of deposition rates and thickness on the electrical resistivity and thermoelectric power of thin iron films. Thin Solid Films. v. 251, p. 99$102,1994$.

SIDDIQUI, Z.N.; KHAN, T. $\mathrm{P}_{2} \mathrm{O}_{5} / \mathrm{SiO}_{2}$ as an efficient heterogeneous catalyst for synthesis of heterocyclic alkene derivatives under thermal solvent-free conditions. Catalysis Science \& Technology, v. 3, p. 2032-2043, 2013.

SKOOG, D. A.; WEST, D. M.; HOLLER, F. J. Fundamentals of analytical chemistry. ed. Sanders college publishing, 1996. 
SOHEYLI, E.; HEKMAT, H.; PARCHAM, F. Variation of electrical conductivity and activation energy in semiconducting glasses with combination of $\mathrm{P}_{2} \mathrm{O}_{5}-\mathrm{CaO}-\mathrm{MoO}_{3}-$ $\mathrm{Li}_{2} \mathrm{O}$. Indian Journal of Pure \& Applied Physics. v. 54, p. 188-192, 2016.

SULLIVAN, M.V.; EIGLER, J.H. Electroless Nickel plating for making ohmic contacts to silicon, J. Electrochem. Soc., v. 104, n. 4, p. 226,1957.

STRAUSSER, Y. E.; HEATON, M. G. Scanning probe microscopy and recent innovations. ed. Amer. Lab., 1991.

TAWATI, D.M.; ADLAN, J.B. Thermoelectric power (TEP) of semiconducting CoONiO- $\mathrm{P}_{2} \mathrm{O}_{5}$ glasses. Ceramics International, v. 30, p. 1737-1739, 2004.

TOMACHEVSKI, F ; SPARVOLI, M ; DOS SANTOS FILHO, S. G. Physical Characterization of $\mathrm{Cu}-\mathrm{Ni}-\mathrm{P}$ Thin Films aiming at $\mathrm{Cu} / \mathrm{Cu}-\mathrm{Ni}-\mathrm{P}$ Thermocouples. In: International Conference on Solid Films and Surfaces (ICSFS 2014), 2015, Rio de Janeiro. IOP Conference Series: Materials Science and Engineering, 2014. v. 76. p. 012010.

TOUIR, R. et al. Electroless deposition of copper in acidic solutions using hypophosphite reducing agent. Journal of Applied Electrochemistry. v. 36, n. 1, jan. 2006.

VANINO, L.; SEITTER, E. Formaldehyde A. Hartlebens Verlag, Wien Leipzig, 1922.

WOLFE, D. B. et al. Fabrication of palladium-based microelectronic devices by micro contact printing. Applied Physics Letters. v. 80, n. 12, p. 2222-2224, 2002.

ZHAO, F. Contrast of electroless plating Ni-P and Ni-Cu-P deposits. Materials Protection. v. 39, n. 3, p. $65-68,2006$.

ŽIVKOVIĆ, Ž. D.; BLEČIĆ, D. The kinetics and mechanism of the process of nickel oxidation, Thermochimica Acta, v. 93, p. 327-331, 1985. 